\title{
CONFLITOS E CONVERGÊNCIAS NA ALCA NUMA PERSPECTIVA DE VANTAGENS COMPARATIVAS REVELADAS DE PAÍSES DAS AMÉRICAS*
}

\author{
Siegfried Bender ${ }^{\S}$
}

\begin{abstract}
RESUMO
Neste artigo calculamos o padrão de vantagens comparativas reveladas de 12 países das Américas no período de 1981 a 1999. A partir desse padrão de vantagens comparativas reveladas averiguamos a similaridade existente entre esses países. O grau de similaridade entre países permite inferir sobre o custo econômico de ajustamentos setoriais resultantes de uma integração comercial entre eles, assim como possibilita fazer conjeturas sobre os incentivos que subgrupos de países têm para atuar conjunta e sistematicamente numa negociação comercial. Os resultados alcançados mostram que os países das Américas podem ser agrupados em três grupos distintos entre si, que o custo econômico de integração comercial entre o conjunto desses países (ALCA) é relativamente elevado e que entre os países sul-americanos há um grupo de países similares entre si, ou bloco natural. Esse grupo de países, portanto, possui um incentivo natural, pela conjugação dos interesses comerciais, para atuar conjuntamente em negociações comerciais, como a de integração regional de comércio da ALCA.
\end{abstract}

Palavras-chave: vantagens comparativas, integração regional de comércio, similaridade entre países, custos de integração comercial.

\begin{abstract}
In this paper the industry sectors' revealed comparative advantages for 12 Americas' countries were calculated from 1981 to 1999 . The countries' revealed comparative advantage patterns are then used to establish the similarity degree among these 12 countries. This similarity degree gives us both an indication of the economic costs in a commercial integration and also some insights about incentives that sub-groups of countries have to act as a group in a negotiation for commercial integration. The results show that these 12 countries can be grouped in three subsets of countries distinct to each other subset, that the economic costs of commercial integration among these 12 countries (ALCA) is relatively high, and that there is a sub-group of South American countries that are similar among them, which therefore have a natural incentive to negotiate as a group in a commercial integration process like ALCA.
\end{abstract}

Key words: comparative advantage, regional commercial integration, similarity among countries, economic costs of commercial integration.

JEL classification: F13, F14, F15.

\footnotetext{
* O autor agradece os valiosos comentários e sugestões recebidos dos pareceristas. Quaisquer erros remanescentes são de responsabilidade do autor.

$\S$ Do Departamento de Economia da FEA-USP. E-mail: sieg@usp.br. Endereço para contato: FEA-USP - Departamento de Economia: Av. Prof. Luciano Gualberto, 908. Cidade Universitária - São Paulo - SP. CEP 05508-010.
}

Recebido em agosto de 2004. Aceito em junho de 2005. 


\section{INTRODUÇÃO}

A regionalização do comércio internacional, em detrimento do multilateralismo tem sido uma tendência crescente desde os anos 1980. O continente americano tem estado entre as regiões mais ativas na proliferação de acordos regionais de comércio. Segundo Jank, Tachinardi e Arashiro (2004) e Salazar-Xirinachs (2002), desde 1990 os países latino-americanos negociaram 12 acordos de livre comércio e estão em processo de negociação de 8 adicionais. Entre esses desenvolvimentos recentes está em discussão desde 1994, pelos 34 países das Américas (exceto Cuba), o Acordo de Livre Comércio das Américas (ALCA). As negociações da ALCA já percorreram várias etapas, e mesmo não tendo sido obedecido seu cronograma inicial há em curso um processo de negociações visando à efetivação final desse acordo de integração comercial.

Nessa fase final de negociações da ALCA, um marco recente foi a reunião ocorrida em Miami em novembro de 2003. Nessa reunião os ministros aceitaram a idéia de uma ALCA "light". Segundo essa abordagem, a ALCA admitirá um acordo em dois níveis. O primeiro é uma espécie de "acordo-base", que será constituído de um conjunto comum de direitos e obrigações a serem compartilhados por todos os 34 países participantes. O segundo nível será composto por acordos bilaterais e plurilaterais entre os países dispostos a assumir compromissos mais profundos do que aqueles estabelecidos no acordo-base. Neste sentido, a nova abordagem à ALCA permite maior flexibilidade a cada país para engajar-se no referido acordo, segundo uma forma que melhor atenda aos seus interesses. Esta flexibilidade inexistia até uma etapa anterior, quando os países ainda estavam comprometidos com um acordo plurilateral, regido pelo princípio do consenso e do "compromisso único" (single undertaking), como fora acordado na reunião de Belo Horizonte em 1998.

Como seria de se esperar, essa inflexão significativa na concepção da ALCA foi controversa. Pelo menos é isso o que nos revela a polarização inicial ocorrida na reunião de Miami entre o MERCOSUL e o grupo dos 14 (liderado pelos EUA), e que resultou em uma posterior convergência em torno das posições do MERCOSUL. O perigo mais visível de seu formato atual como ALCA "light" está, todavia, em que esta possa se transformar numa espécie de ALADI: uma colcha de retalhos com distintos níveis de compromisso, o que, por sua vez, tende a gerar um elevado custo de transação intrabloco. Neste caso perverso, o alto custo de transação pode limitar significativamente os ganhos com a criação de comércio no âmbito da ALCA e desfigurar a própria integração hemisférica pretendida.

A despeito desses problemas em potencial, o fato da ALCA "light" ter sido aprovada demonstra, em primeiro lugar, que essa abordagem teve certo respaldo de boa parte dos 34 países participantes. Mas a adoção da ALCA "light” sugere, igualmente, que para muitos países os custos de integração foram percebidos como importantes. Portanto, essa nova abordagem é conveniente (ou funcional) por ser mais flexível e, assim, admitir uma melhor compatibilização com as contrapressões protecionistas domésticas que resultam dessa integração hemisférica potencial e efetiva. Muito possivelmente, por essas razões, uma parte dos países, principalmente sul-americanos, contrapôs-se aos interesses e pressões norte-americanas (e NAFTA), cuja importância do mercado representa, por si só, uma enorme força de persuasão. Essa oposição sul-americana levou a reunião de Miami a um desfecho, de certo modo inesperado, que visivelmente minou as pretensões norte-americanas iniciais.

Em suma, a definição por uma abordagem de ALCA “light” dividiu profundamente os países nas Américas, mesmo os sul-americanos. De um lado alinharam-se aqueles que concordavam com uma definição próxima aos objetivos dos EUA e, de outro, alinharam-se aqueles que simpatizavam com os pontos de vista defendidos pelo MERCOSUL. Esse fato suscita pelo menos duas questões. Primeira, até que ponto pode-se esperar uma atuação conjunta de países sul-americanos nesta fase 
final das negociações, que envolvem o aspecto crucial de acesso a mercados? Segunda, o que levaria esses países a preferir uma união com seus vizinhos a atuar de modo isolado (e mais próximo às ambições dos EUA) na mesa de negociações? O objetivo do presente artigo é, primeiramente, tirar inferências acerca da possibilidade de haver ou não distintos níveis de custos econômicos de integração comercial na ALCA e percebidos como tal por alguns dos países em contraposição a outros. Caso os custos de integração sejam significativamente distintos, eles podem ter contribuído para o surgimento desses dois agrupamentos de países nas discussões em Miami. Um segundo objetivo do artigo é especular sobre eventuais incentivos que esses países têm para atuar conjuntamente nas negociações e adotar uma posição pró ou contra a concepção de integração hemisférica aos moldes da ALCA "light". A análise dessas questões será desenvolvida com base no padrão de vantagens comparativas inerentes a cada país. A partir dessa perspectiva, iremos verificar quão similares ou divergentes são os países e, assim, inferir de que maneira isso pode afetar tanto sua percepção dos custos de integração quanto uma possível postura conjunta dos mesmos nas negociações de acesso a mercados, nessa etapa final da ALCA.

$\mathrm{O}$ artigo compreende, além desta introdução, mais sete seções. Na seção 2 é explicitada a metodologia; na seção 3 analisam-se as vantagens comparativas reveladas de países nas Américas; nas seções 4 e 5 são mostrados os diferentes níveis de custos de integração comercial e sua associação com o padrão de vantagens comparativas; nas seções 6 e 7 é analisada a similaridade entre os países americanos aqui considerados; na seção 8 apresentam-se as considerações finais.

\section{Metodologia do ESTUdo}

Para os objetivos deste artigo calcular-se-á o padrão de vantagens comparativas reveladas em vários países das Américas. Como se sabe, o padrão de comércio de um país pode refletir as diferenças de competitividade entre países em termos de custos relativos e de fatores não-preço. A abordagem de "vantagem comparativa revelada" (VCR), proposta por Balassa, assumiu que o padrão de vantagens comparativas poderia ser observado a partir dos dados de comércio. Essa abordagem ("revelada”) tem suas limitações. Em princípio, vantagens comparativas são definidas em termos de preços autárquicos, variáveis não observáveis, enquanto que os dados de comércio utilizados refletem situações de pós-comércio. Disto resulta, por exemplo, que alterações nas VCR não conseguem distinguir melhorias na dotação de fatores e/ou de tecnologia dos efeitos provocados por políticas de comércio que distorçam os fluxos comerciais. No entanto, a despeito das várias limitações teóricas, em Hillman (1980) e em Marchese e de Simone (1989) mostra-se que o cômputo dos índices de VCR apresenta uma transformação monotônica com relação aos preços autárquicos (pré-comércio) quando se efetuam comparações entre países. Marchese e de Simone mostram, ademais, que de modo geral a alteração no índice de VCR é consistente com alterações na dotação relativa de recursos e de produtividade nos países. Em conseqüência disso, numa comparação entre países um maior índice de VCR indica, em geral, uma maior vantagem comparativa na exportação de determinada mercadoria.

Em adição, há argumentos que apontam ser conveniente a utilização de índices de VCR, pois, a despeito de suas reconhecidas limitações teóricas, esses indicadores se constituem nas medidas disponíveis para inferir sobre o padrão específico de vantagens comparativas de um país e, por isso mesmo, têm sido largamente utilizados em trabalhos aplicados ao comércio. Finalmente, mesmo considerando que políticas comerciais que distorçam os fluxos de comércio causam vieses na informação gerada por esses índices, o presente estudo baseia-se numa análise do comportamento do padrão de VCR ao longo do tempo. Neste enfoque de análise temporal, o que de fato importa, para 
que a indicação de ganhos e perdas de VCR não esteja comprometida, é que o grau de distorção imposto aos fluxos de comércio não seja crescente no tempo. Em suma, os indicadores de VCR guardam uma relação com o padrão de vantagens comparativas de um país, e a análise aqui efetuada minimiza potenciais distorções nas estimativas de VCR que podem ser geradas por políticas comerciais ativistas.

A mensuração das vantagens comparativas seguiu a abordagem tradicional, ${ }^{1}$ com a utilização do índice de vantagens comparativas reveladas (VCR) de Balassa (1965, 1977, 1979), que é definido, para determinada indústria i no país j, como sendo:

$\mathrm{VCR}_{\mathrm{ij}}=\left[\frac{X_{i j}}{\sum_{i} X_{i j}}\right] /\left[\frac{X_{i w}}{\sum_{i} X_{i w}}\right]$

onde $\mathrm{X}_{\mathrm{ij}}$ e $\mathrm{X}_{\mathrm{iw}}$ são, respectivamente, as exportações do país j e as mundiais na indústria i, enquanto $\sum X_{i j}$ e $\sum X_{i w}$ são, respectivamente, o total das exportações do país j e o total das mundiais, obtidos pela agregação de todos os setores i considerados. Os dados de exportação mundiais utilizados para o cálculo do índice foram aqui construídos a partir da agregação das exportações das indústrias manufatureiras dos 48 maiores países constantes no banco de dados da UNIDO (2002), compreendendo todos os países da OCDE, oito países da América do Sul, todos os países da América do Norte, os maiores países no sudeste da Ásia (exceto China e Taiwan), do sul da Ásia, do Pacífico do Sul e Oceania, e da África e Oriente Médio.

O banco de dados da UNIDO (2002) informa as exportações e importações anuais de 81 setores industriais manufatureiros a 4-dígitos de classificação ISIC (International Standard Industry Classification) para 73 países no período 1981-1999. Os dados desses setores foram agregados para uma classificação ISIC a 3-dígitos, resultando em 31 setores industriais. Esta classificação e a compatibilização de 3 com 4 dígitos do código ISIC encontram-se discriminados na Tabela A1, anexa.

Os países das Américas considerados no texto principal deste estudo são os seguintes: Argentina, Bolívia, Chile, Colômbia, Equador, Peru, Uruguai, Venezuela, México, Canadá e Estados Unidos. No caso da América do Sul, a omissão relevante no texto principal é a do Brasil, ${ }^{2}$ e decorre de dois fatos: (1) o País não consta do banco de dados da UNIDO utilizado na presente análise; e (2) a classificação dos dados industriais e de exportação disponíveis para o Brasil não é, a princípio, imediatamente compatível com o código ISIC. Note-se que também o Paraguai não está presente no estudo porque não consta do banco de dados da UNIDO. Todavia, no anexo 2 efetuamos uma compatibilização própria da nomenclatura NCM com o código ISIC e então procedemos à análise do conjunto desses países com a inclusão do Brasil.

Assim sendo, calculamos e analisamos para 12 países das Américas os valores do índice de VCR (Balassa) para setores da indústria manufatureira no período de 1981 a 1999. A seguir, analisamos como a similaridade do padrão de vantagens comparativas entre esses países implica maiores ou menores custos de integração na ALCA, e também, dessa perspectiva de VCR, conjeturamos

1 A literatura tem sugerido vários índices de vantagens comparativas reveladas, cuja utilização depende do tipo, da periodicidade e da qualidade dos dados disponíveis. Não há algum claramente superior. Todos tem suas vantagens e desvantagens, sendo o índice de Balassa o mais utilizado. Ver Vollrath (1991).

2 No anexo 2 deste artigo efetuamos uma compatibilização própria entre a nomenclatura NCM (Brasil) e o código ISIC (UNIDO), e procedemos à análise dos países das Américas com a inclusão do Brasil. A compatibilização efetuada está, sem dúvida, sujeita a problemas e críticas, no caso brasileiro, quanto à composição das exportações de segmentos em certas indústrias e, por isso, mantivemos a análise com inclusão do Brasil só no anexo. Todavia, os resultados alcançados quanto ao padrão de vantagens comparativas do Brasil resultou ser condizente com a expectativa, e a análise pode ser efetuada sem maiores distorções aparentes. 
sobre a viabilidade de grupos de países sul-americanos atuarem de modo conjunto ou não nas negociações da ALCA.

\section{VANTAGENS COMPARATIVAS REVELADAS DE PAÍSES}

Como já salientado, o cômputo dos índices de VCR foi efetuado anualmente para o período de 1981-1999, e a seguir foram compostos os sucessivos subperíodos de três anos (1981-1983; 1984-1986 etc...), perfazendo um total de 7 subperíodos. Para cada um desses subperíodos foi calculada a média dos valores anuais dos índices de VCR por setor. A análise do padrão de setores com VCR dos países baseou-se nessas médias, as quais podem ser interpretadas como o "verdadeiro" indicador de VCR por setor, país e subperíodo. Por questão de clareza, a Tabela 1 reporta somente os valores dos subperíodos inicial (1981-1983) e final (1997-1999), e na coluna de especificação dos setores a indicação VCR mostra quantos setores de VCR de cada país existem no subperíodo.

Tabela 1 - Índices de vantagens comparativas reveladas (Balassa) em países das Américas

\begin{tabular}{|c|c|c|c|c|c|c|c|c|c|c|c|c|}
\hline & \multicolumn{2}{|c|}{ ARGENTINA } & \multicolumn{2}{|c|}{ BOLIVIA } & \multicolumn{2}{|c|}{ CHILE } & \multicolumn{2}{|c|}{ COLÔMBIA } & \multicolumn{2}{|c|}{ EQUADOR } & \multicolumn{2}{|c|}{ PERU } \\
\hline & $81-83$ & 97-99 & $81-83$ & $97-99$ & $81-83$ & $97-99$ & $81-83$ & $97-99$ & $81-83$ & $97-99$ & $81-83$ & $97-99$ \\
\hline 311 & 6,99 & 8,95 & 1,27 & 7,27 & 1,57 & 2,58 & 8,09 & 6,70 & 6,94 & 9,60 & 3,10 & 5,52 \\
\hline 312 & 0,36 & 1,34 & 2,68 & 1,37 & 3,57 & 3,36 & 0,02 & 0,05 & 24,90 & 7,77 & 8,78 & 10,52 \\
\hline 313 & 0,39 & 1,62 & 0,34 & 0,86 & 1,10 & 3,99 & 0,07 & 0,39 & 0,16 & 0,09 & 0,06 & 0,14 \\
\hline 314 & 0,03 & 0,41 & 0,00 & 1,06 & 0,00 & 0,11 & 0,20 & 0,19 & 1,31 & 0,08 & 0,02 & 0,18 \\
\hline 321 & 0,77 & 0,52 & 0,26 & 0,71 & 0,03 & 0,37 & 1,09 & 1,78 & 0,14 & 0,98 & 3,13 & 2,51 \\
\hline 322 & 0,51 & 0,22 & 0,19 & 0,96 & 0,01 & 0,17 & 1,46 & 3,00 & 0,69 & 0,73 & 0,45 & 2,15 \\
\hline 323 & 15,11 & 10,45 & 0,29 & 2,88 & 0,07 & 0,37 & 3,36 & 1,52 & 0,01 & 0,44 & 0,83 & 0,24 \\
\hline 324 & 0,17 & 0,67 & 0,02 & 0,27 & 0,02 & 0,29 & 1,19 & 1,17 & 0,00 & 0,28 & 0,38 & 0,06 \\
\hline 331 & 0,01 & 0,28 & 3,17 & 6,93 & 2,08 & 5,39 & 0,44 & 0,33 & 4,27 & 4,19 & 0,49 & 1,08 \\
\hline 332 & 0,05 & 0,63 & 0,00 & 1,27 & 0,01 & 0,51 & 0,26 & 0,39 & 0,06 & 0,26 & 0,12 & 0,09 \\
\hline 341 & 0,10 & 0,64 & 0,00 & 0,24 & 2,66 & 2,30 & 0,57 & 0,96 & 0,15 & 0,60 & 0,02 & 0,09 \\
\hline 342 & 0,96 & 0,98 & 0,01 & 0,24 & 0,28 & 1,71 & 3,04 & 3,62 & 0,02 & 0,37 & 0,18 & 0,39 \\
\hline 351 & 0,74 & 0,87 & 0,11 & 0,23 & 0,78 & 0,96 & 0,42 & 1,68 & 0,10 & 0,38 & 0,64 & 0,45 \\
\hline 352 & 0,93 & 0,95 & 0,01 & 0,04 & 0,07 & 0,30 & 0,52 & 1,80 & 0,27 & 0,98 & 0,67 & 0,46 \\
\hline 353 & 2,32 & 2,52 & 0,32 & 0,68 & 0,55 & 0,31 & 2,57 & 4,23 & 4,05 & 7,38 & 5,81 & 1,90 \\
\hline 354 & 0,76 & 1,69 & 0,00 & 0,00 & 0,04 & 0,54 & 0,48 & 1,60 & 0,00 & 0,05 & 0,01 & 0,15 \\
\hline 355 & 0,25 & 0,87 & 0,00 & 0,02 & 0,22 & 0,75 & 0,15 & 1,06 & 0,00 & 1,81 & 0,07 & 0,33 \\
\hline 356 & 0,12 & 0,46 & 0,00 & 0,20 & 0,01 & 0,42 & 0,87 & 1,06 & 0,29 & 0,86 & 0,21 & 0,25 \\
\hline 361 & 0,06 & 0,29 & 0,00 & 0,15 & 0,20 & 0,61 & 1,39 & 1,89 & 0,63 & 3,54 & 0,57 & 0,91 \\
\hline 362 & 0,51 & 0,41 & 0,05 & 0,51 & 0,05 & 0,36 & 1,12 & 1,56 & 0,00 & 1,33 & 0,53 & 0,47 \\
\hline 369 & 0,24 & 0,51 & 0,02 & 0,04 & 0,01 & 0,20 & 1,99 & 2,84 & 0,25 & 0,80 & 0,75 & 0,72 \\
\hline 371 & 1,05 & 1,63 & 0,00 & 0,04 & 0,26 & 0,34 & 0,23 & 1,44 & 0,00 & 0,27 & 0,12 & 0,31 \\
\hline 372 & 0,83 & 0,72 & 27,31 & 5,42 & 21,10 & 23,15 & 0,03 & 0,38 & 0,10 & 0,20 & 4,04 & 16,26 \\
\hline 381 & 0,35 & 0,32 & 0,24 & 0,16 & 0,10 & 0,34 & 0,73 & 0,69 & 0,10 & 0,65 & 0,41 & 0,13 \\
\hline 382.1 & 0,14 & 0,30 & 0,00 & 0,16 & 0,02 & 0,03 & 0,09 & 0,05 & 0,06 & 0,08 & 0,04 & 0,03 \\
\hline 382.2 & 0,37 & 0,20 & 0,14 & 0,24 & 0,03 & 0,11 & 0,12 & 0,15 & 0,20 & 0,10 & 0,10 & 0,06 \\
\hline 383.1 & 0,14 & 0,24 & 0,00 & 0,05 & 0,05 & 0,04 & 0,15 & 0,23 & 0,05 & 0,06 & 0,00 & 0,04 \\
\hline 383.2 & 0,09 & 0,08 & 0,00 & 0,03 & 0,02 & 0,04 & 0,10 & 0,14 & 0,17 & 0,09 & 0,10 & 0,04 \\
\hline 384 & 0,18 & 0,86 & 0,01 & 0,93 & 0,10 & 0,14 & 0,06 & 0,17 & 0,01 & 0,29 & 0,07 & 0,01 \\
\hline 385 & 0,09 & 0,12 & 0,00 & 0,23 & 0,03 & 0,02 & 0,16 & 0,16 & 0,00 & 0,01 & 0,03 & 0,20 \\
\hline 390 & 0,17 & 0,11 & 0,08 & 5,73 & 0,08 & 0,11 & 0,34 & 0,59 & 0,13 & 0,99 & 2,06 & 1,98 \\
\hline VCR & 4 & 7 & 4 & 8 & 6 & 7 & 10 & 16 & 5 & 7 & 6 & 8 \\
\hline
\end{tabular}


Tabela 1 - Índices de vantagens comparativas reveladas (Balassa) em países das Américas (cont.)

\begin{tabular}{|c|c|c|c|c|c|c|c|c|c|c|}
\hline & \multicolumn{2}{|c|}{ URUGUAI } & \multicolumn{2}{|c|}{ VENEZUELA } & \multicolumn{2}{|c|}{ MÉXICO } & \multicolumn{2}{|c|}{ EUA } & \multicolumn{2}{|c|}{ CANADÁ } \\
\hline & $81-83$ & $97-99$ & $81-83$ & $97-99$ & $81-83$ & $97-99$ & $81-83$ & $97-99$ & $81-83$ & $97-99$ \\
\hline 311 & 7,75 & 8.69 & 0,03 & 0,69 & 1,42 & 0,43 & 0,81 & 0,75 & 0,63 & 0,74 \\
\hline 312 & 0,61 & 0,82 & 0,06 & 1,23 & 4,97 & 0,74 & 0,91 & 1,04 & 0,48 & 0,83 \\
\hline 313 & 2,37 & 3,71 & 0,01 & 0,85 & 2,12 & 1,00 & 0,20 & 0,33 & 0,92 & 0,68 \\
\hline 314 & 0,01 & 2,49 & 0,71 & 4,75 & 0,20 & 0,14 & 2,27 & 2,04 & 0,07 & 0,07 \\
\hline 321 & 3,65 & 4,14 & 0,00 & 0,21 & 0,55 & 0,90 & 0,45 & 0,52 & 0,12 & 0,35 \\
\hline 322 & 4,27 & 3,11 & 0,00 & 0,03 & 0,61 & 2,22 & 0,24 & 0,48 & 0,23 & 0,31 \\
\hline 323 & 18,82 & 20,02 & 0,00 & 0,37 & 0,56 & 0,78 & 0,57 & 0,46 & 0,18 & 0,15 \\
\hline 324 & 1,93 & 1,53 & 0,02 & 0,11 & 0,85 & 0,72 & 0,16 & 0,21 & 0,16 & 0,14 \\
\hline 331 & 0,01 & 0,27 & 0,01 & 0,05 & 0,85 & 0,38 & 0,70 & 0,69 & 4,50 & 5,45 \\
\hline 332 & 0,20 & 0,62 & 0,01 & 0,07 & 0,54 & 1,76 & 0,42 & 0,72 & 0,83 & 2,06 \\
\hline 341 & 0,29 & 0,77 & 0,05 & 0,63 & 0,26 & 0,25 & 0,86 & 0,88 & 4,82 & 3,38 \\
\hline 342 & 0,38 & 0,63 & 0,15 & 0,38 & 1,86 & 0,67 & 1,17 & 1,27 & 0,62 & 0,98 \\
\hline 351 & 0,17 & 0,54 & 0,27 & 1,88 & 1,47 & 0,41 & 1,20 & 1,23 & 0,74 & 0,81 \\
\hline 352 & 0,89 & 0,66 & 0,06 & 0,47 & 0,80 & 0,42 & 1,26 & 0,94 & 0,20 & 0,39 \\
\hline 353 & 0,13 & 0,51 & 18,55 & 19,66 & 2,00 & 0,33 & 0,53 & 0,58 & 0,64 & 0,76 \\
\hline 354 & 0,00 & 0,02 & 0,12 & 0,46 & 0,32 & 0,24 & 1,19 & 1,44 & 0,26 & 0,92 \\
\hline 355 & 0,83 & 1,77 & 0,02 & 1,33 & 0,20 & 0,38 & 0,61 & 0,83 & 0,93 & 1,08 \\
\hline 356 & 0,20 & 0,43 & 0,05 & 0,55 & 0,83 & 1,15 & 0,59 & 1,06 & 0,18 & 0,96 \\
\hline 361 & 1,90 & 1,61 & 0,03 & 1,34 & 1,20 & 1,34 & 0,26 & 0,50 & 0,11 & 0,07 \\
\hline 362 & 0,84 & 0,77 & 0,05 & 1,29 & 2,76 & 1,32 & 0,87 & 0,93 & 0,29 & 0,65 \\
\hline 369 & 0,46 & 1,15 & 0,08 & 3,24 & 1,47 & 0,80 & 0,46 & 0,47 & 0,52 & 0,81 \\
\hline 371 & 0,09 & 0,32 & 0,47 & 4,34 & 0,54 & 0,77 & 0,25 & 0,41 & 0,64 & 0,67 \\
\hline 372 & 0,01 & 0,22 & 2,73 & 6,22 & 4,77 & 0,58 & 0,60 & 0,63 & 2,30 & 2,28 \\
\hline 381 & 0,09 & 0,11 & 0,07 & 0,60 & 0,63 & 1,08 & 0,81 & 0,84 & 0,50 & 0,95 \\
\hline 382.1 & 0,01 & 0,03 & 0,02 & 0,12 & 0,41 & 0,47 & 0,97 & 1,23 & 1,35 & 0,79 \\
\hline 382.2 & 0,02 & 0,06 & 0,05 & 0,05 & 0,45 & 0,79 & 1,84 & 1,18 & 0,40 & 0,53 \\
\hline 383.1 & 0,05 & 0,37 & 0,04 & 0,15 & 0,77 & 2,30 & 0,70 & 1,03 & 0,10 & 0,44 \\
\hline 383.2 & 0,07 & 0,03 & 0,01 & 0,07 & 0,95 & 1,82 & 1,18 & 1,10 & 0,41 & 0,48 \\
\hline 384 & 0,04 & 0,2 & 0,04 & 0,25 & 0,70 & 1,19 & 1,17 & 1,14 & 1,85 & 1,83 \\
\hline 385 & 0,01 & 0,09 & 0,01 & 0,05 & 0,40 & 0,84 & 1,73 & 1,51 & 0,48 & 0,39 \\
\hline 390 & 0,06 & 0,11 & 0,07 & 0,20 & 0,79 & 0,97 & 0,84 & 0,73 & 0,42 & 0,48 \\
\hline VCR & 7 & 10 & 2 & 10 & 10 & 10 & 9 & 12 & 5 & 6 \\
\hline
\end{tabular}

Atentando para o fato que os valores em negrito na Tabela 1 acima indicam setores com vantagem comparativa revelada ("VCR $\geq 1$ "), a análise do padrão de vantagem comparativa por país entre o início e final do período mostra os seguintes resultados:

(1) Nenhum país apresentou perda no número total de setores com VCR. Quase todos os países apresentaram significativa melhoria no desempenho externo de suas economias, com aumento do grau de diversificação das exportações. Isto é, o número de setores com VCR ao final de período é maior ou no mínimo igual ao número total de setores com VCR no início de período;

(2) Todos os países (à exceção do México) mantêm o padrão inicial ${ }^{3}$ dos setores com VCR ao longo de todo o período 1981-1999. Em adição, entre o início e final de período há aqueles que apresentam ganhos expressivos com adição de muitos novos setores com VCR no padrão inicial, sendo este os casos da Argentina, Bolívia e Colômbia. Além disso, há aqueles que apresentam ganhos significativos de VCR (mas menor do que 50\% do total inicial de setores com VCR)

3 Admite-se que o país possa perder no máximo 1 setor constante do padrão inicial de VCR. 
no padrão inicial de VCR, sendo este os casos do Equador, Peru, Uruguai, Venezuela ${ }^{4}$ e EUA. Finalmente, há os casos do Chile e do Canadá, que obtêm pouco ganho de novos setores com VCR, pois incorporam somente mais um setor ao padrão inicial de setores com VCR;

(3) O caso do México apresenta resultados mistos. Em primeiro lugar, o número de setores com VCR eleva-se expressiva e sistematicamente do início até o subperíodo 1993-1995, quando registra uma elevação de um total de 10 para 15 setores com VCR. Todavia, a partir desse máximo registra-se um retorno para um total de 10 setores com VCR no final do período (1997-1999). O mais importante nessa dinâmica é, entretanto, o fato de o padrão de vantagens comparativas se alterar substancialmente. Até o subperíodo 1993-1995 o aumento do número de setores com VCR ocorre com a manutenção do padrão inicial de VCR. Após 1993-1995, há perda de VCR em alguns setores (311, 312, 342, 351, 353, 369 e 372) e incorporação de outros (322, 332, 356, 381, 383.1, 383.2 e 384). Sem dúvida, o engajamento do México no NAFTA é a causa básica dessa dinâmica inicial, e em período mais recente a perda de suas exportações para países como a China no mercado do NAFTA provavelmente constitui a razão da queda de sua performance de VCR na fase final do período (pós-1995).

Uma descrição alternativa e complementar ao padrão de VCR dos países das Américas com a classificação ISIC a 3-dígitos, como exposto acima, pode ser obtida quando reclassificamos as exportações desses países segundo o código a 1-dígito da OCDE. Tal classificação ordena as indústrias como: (1) recurso-intensivas, (2) trabalho-intensivas, (3) escala-intensivas, (4) bens diferenciados e (5) baseadas em ciência. Portanto, consiste numa classificação de indústrias que guarda uma íntima relação com as fontes (ou teorias) de comércio entre países. A Tabela 2 mostra o resultado dessa reordenação dos setores segundo o código OCDE e o cálculo do correspondente padrão de VCR para os subperíodos inicial (1981-1983) e final (1997-1999) para os países considerados nesta análise (para o Brasil, ver anexo 2).

A partir da Tabela 2, as características do padrão de VCR para os países das Américas são igualmente evidentes e concordantes com o disposto na Tabela 1:

(1) Para todos os países, exceto o México, há estabilidade do padrão de VCR, e nos anos 1990, em alguns países, há adição de novo setor (indústria 1-dígito) de VCR;

(2) No caso dos países sul-americanos, o padrão típico é ter VCR em indústrias recurso-intensivas, e em alguns casos (Bolívia, Colômbia, Peru e Uruguai) adicionam-se às VCR as indústrias trabalho-intensivas;

(3) Os EUA têm um padrão de VCR em indústrias com elevada participação de capital (“capital humano" - indústrias 4 e 5 - e "capital não-humano" - indústrias 3 e 4);

(4) O Canadá tem VCR em indústrias recurso-intensivas e intensivas em capital;

(5) O México, a partir de um padrão de VCR tipicamente sul-americano nos anos 1980 e início dos anos 1990, modifica sua estrutura de VCR para indústrias intensivas em trabalho e intensivas em capital a partir de 1995;

(6) Nessa classificação, o padrão de VCR dos países sul-americanos e o dos países do NAFTA é definido e radicalmente distinto um do outro. Por isso, pode-se fazer uma conjetura acerca do

4 No caso da Venezuela, o subperíodo inicial mais adequado para comparação intertemporal não é o primeiro (1981-1983), mas sim o segundo (1984-1986). A razão disso é que no primeiro subperíodo os preços do petróleo ainda estavam elevados com o segundo choque do petróleo (1979-80), resultando que as receitas de exportação de petróleo e de seus derivados camuflam todas as demais exportações. Isso gera o resultado estranho de somente haver dois setores com VCR nesse subperíodo inicial, ao passo que no subperíodo seguinte (1984-1986), por exemplo, o total de setores com VCR salta para 8.

5 Em Memedovic (1994), seguindo OCDE (1987), mostra-se a compatibilização entre a classificação ISIC e a da OCDE. 
padrão de VCR após a constituição da ALCA. Ao que tudo indica, os países sul-americanos concentrarão suas exportações intrabloco no padrão atual, constituído de exportações (e VCR) em indústrias recurso e trabalho-intensivas, enquanto que os países do NAFTA reforçarão suas exportações intrabloco em indústrias escala-intensivas, bens diferenciados e baseadas em ciência.

Tabela 2 - Índice de VCR (Balassa) de países das Américas - Código OCDE

\begin{tabular}{|c|c|c|c|c|c|c|c|c|}
\hline \multirow[b]{2}{*}{ INDÚSTRIASIPERÍODO } & \multicolumn{2}{|c|}{ ARGENTINA } & \multicolumn{2}{|c|}{ BOLIVIIA } & \multicolumn{2}{|c|}{ CHILE } & \multicolumn{2}{|c|}{ COLÔMBIA } \\
\hline & $81-83$ & $97-99$ & $81-83$ & $97-99$ & $81-83$ & $97-99$ & $81-83$ & $97-99$ \\
\hline 1-Recurso-Intensivas & 3,17 & 3,81 & 4,38 & 3,51 & 4,07 & 5,39 & 3,34 & 2,99 \\
\hline 2-Trabalho-Intensivas & 0,48 & 0,39 & 0,20 & 1,16 & 0,05 & 0,31 & 0,93 & 1,48 \\
\hline 3-Escala-Intensivas & 0,48 & 0,94 & 0,04 & 0,52 & 0,29 & 0,43 & 0,33 & 0,84 \\
\hline 4-Bens Diferenciados & 0,16 & 0,19 & 0,07 & 0,13 & 0,03 & 0,09 & 0,11 & 0,17 \\
\hline \multirow[t]{2}{*}{ 5-Baseadas em Ciência } & 0,59 & 0,30 & 0,00 & 0,95 & 0,05 & 0,08 & 0,23 & 0,51 \\
\hline & \multicolumn{2}{|c|}{ EQUADOR } & \multicolumn{2}{|c|}{ PERU } & \multicolumn{2}{|c|}{ URUGUAI } & \multicolumn{2}{|c|}{ VENEZUELA } \\
\hline INDÚSTRIASIPERÍODO & $81-83$ & $97-99$ & $81-83$ & $97-99$ & $81-83$ & $97-99$ & $81-83$ & $97-99$ \\
\hline 1-Recurso-Intensivas & 4,22 & 4,77 & 3,16 & 4,93 & 3,06 & 3,94 & 4,29 & 3,97 \\
\hline 2-Trabalho-Intensivas & 0,20 & 0,79 & 1,60 & 1,53 & 2,06 & 2,10 & 0,03 & 0,26 \\
\hline 3-Escala-Intensivas & 0,05 & 0,45 & 0,23 & 0,18 & 0,15 & 0,40 & 0,17 & 1,06 \\
\hline 4-Bens Diferenciados & 0,16 & 0,10 & 0,08 & 0,08 & 0,03 & 0,08 & 0,03 & 0,09 \\
\hline \multirow[t]{2}{*}{ 5-Baseadas em Ciência } & 0,10 & 0,26 & 0,21 & 0,13 & 0,28 & 0,19 & 0,02 & 0,13 \\
\hline & \multicolumn{2}{|c|}{ MÉXICO } & \multicolumn{2}{|c|}{ EUA } & \multicolumn{2}{|c|}{ CANADÁ } & & \\
\hline INDÚSTRIASIPERÍODO & $81-83$ & $97-99$ & $81-83$ & $97-99$ & $81-83$ & $97-99$ & & \\
\hline 1-Recurso-Intensivas & 1,90 & 0,47 & 0,66 & 0,68 & 1,66 & 1,76 & & \\
\hline 2-Trabalho-Intensivas & 0,64 & 1,29 & 0,52 & 0,59 & 0,32 & 0,64 & & \\
\hline 3-Escala-Intensivas & 0,93 & 0,97 & 0,94 & 1,02 & 1,25 & 1,39 & & \\
\hline 4-Bens Diferenciados & 0,63 & 1,32 & 1,17 & 1,05 & 0,48 & 0,52 & & \\
\hline 5-Baseadas em Ciência & 0,51 & 0,76 & 2,33 & 1,52 & 0,67 & 0,56 & & \\
\hline
\end{tabular}

Em suma, observou-se que nenhum dos 11 países aqui considerados apresentou perda no número total de setores com VCR. Isto é, aparentemente houve uma melhora generalizada no desempenho externo desses países, com significativo aumento do grau de diversificação das exportações para a quase totalidade dessas economias entre o início e final de período, sendo que para alguns países o aumento de setores com VCR foi expressivo. Este fato pode, eventualmente, decorrer de um aumento geral da "competitividade internacional" das economias dos países das Américas, em especial dos sul-americanos nesse período. A melhoria no desempenho externo das economias das Américas ocorre com a adição, ao padrão original de VCR, de novos setores com vantagem comparativa revelada. O México constitui a única exceção a esse padrão, pois muda substancialmente seu padrão de vantagens comparativas reveladas entre o início e o final de período. A melhora dos fundamentos macroeconômicos dos países da América Latina, decorrentes tanto da estabilização econômica quanto da abertura comercial ocorrida na década dos 1980 e início dos 1990 nessa região, muito possivelmente pode ser uma explicação para o bom resultado de ganhos de VCR registrados nesses países. ${ }^{6}$ Outro fato importante, que certamente impulsionou a atividade exportadora

6 Esse resultado de significativos ganhos de vantagem comparativa na América Latina entre a década dos anos 1980 e 1990 também foi registrada em outro estudo (ver Bender e Li, 2002a, 2002b). 
da Argentina, do Uruguai e do México, consistiu da criação dos blocos regionais de comércio do MERCOSUL e do NAFTA no início dos anos 1990.

\section{CUSTOS DE AJUSTAMENTO EM INTEGRAÇÃO REGIONAL DE COMÉRCIO}

A literatura sobre integração econômica regional - ver Balassa (1965, 1967); Aquino (1978); Greenaway e Hine (1991); Greenaway (1987) - tem destacado distintos níveis de custos de ajustamento na dependência de os fluxos comerciais dominantes serem de natureza "intra ou interindústria”. No caso de comércio intra-indústria, o que se ressalta é o fato de que, por estar baseado em economias de escala e concorrência monopolística, a integração comercial ocorre com menor fricção e menores custos de ajustamento setoriais, ao passo que no caso de comércio interindústria, mais condizente com um padrão de comércio baseado em vantagens comparativas tradicionais tipo Heckscher-Ohlin, a integração comercial envolve significativas fricções e altos custos de ajustamento setorial. A justificação para o elevado custo de ajustamento setorial quando o padrão de comércio é do tipo interindústria decorre justamente do fato de a atividade econômica nos países ser forçada, após o acordo e a liberalização do comércio intrabloco, a se realinhar e concentrar-se segundo o padrão de vantagens comparativas em cada país participante do acordo regional. Naturalmente, esse tipo de reajustamento setorial é problemático, pois envolve a expansão de certos setores e indústrias e a contração (e até eliminação) de outros setores e indústrias. Por outro lado, no caso de o padrão de comércio ser do tipo intra-indústria o reajustamento setorial é minimizado pelo fato de possibilitar que os países envolvidos se especializem em linhas de produto de uma mesma indústria, levando, assim, a um reajustamento setorial menor em resposta à liberalização comercial intrabloco promovida pelo acordo de integração regional de comércio.

Qual o fundamento para essa diferença ser atribuída aos custos de ajustamento numa integração comercial? Em primeiro lugar, por causa das diferenças existentes nos requerimentos de insumos e fatores entre os setores em expansão (setores exportadores e/ou com vantagens comparativas) e os setores em contração (setores competidores às importações e/ou com desvantagens comparativas). Em segundo lugar, devido à existência de certo grau de especificidade de insumos e fatores nos diferentes setores. Assim sendo, quanto mais distintos forem os setores em contração relativamente àqueles em expansão, maior será a alteração de preços relativos provocada pela liberalização intrabloco. Isto, por sua vez, induz à necessidade de um elevado grau de reajustamento setorial em termos da composição ótima da atividade produtiva na economia, sendo este, justamente, o caso assumido para os setores associados ao comércio interindústria. Portanto, da relativa maior dissimilaridade de requerimentos de insumos e fatores no caso interindústria resulta o fato de o desempregado nos setores em contração não ser facilmente reempregado nos setores em expansão sem completa reciclagem. Por seu turno, a especificidade significativamente distinta dos tipos de capital e insumos intermediários no caso interindústria também não admite seu reemprego sem altos custos de ajustamento (elevadas perdas de capital) e readequação "física" dos mesmos nos setores em expansão da economia. Em suma, supõe-se que os custos de ajustamento setorial decorrentes da liberalização comercial intrabloco são expressivos quando o padrão de comércio predominante é do tipo interindústria.

No caso de setores de comércio intra-indústria, no entanto, por se tratar da troca de produtos semelhantes, assume-se que estes têm requerimentos (e especificidades) similares de insumos e fatores. Neste caso, as alterações de preços relativos ocasionadas pela integração regional de comércio são menos intensas e necessitam de menores reajustes setoriais associados ao mix ótimo de atividade produtiva na economia. Quanto aos processos produtivos, assume-se que estes não são excessiva- 
mente distintos nesses setores. Em conseqüência disto, o desempregado nos setores competidores de importados (setores em contração) podem ser reempregados, com pouca reciclagem, nos setores exportadores (setores em expansão). Um argumento semelhante pode ser feito com relação ao fator capital e demais insumos produtivos. Ou seja, considerações desse tipo levaram muitos analistas a admitir que o ajustamento setorial decorrente da liberalização comercial intrabloco é mais "suave" quando o padrão de comércio predominante é do tipo intra-indústria. Esta suposição, por outro lado, é corroborada nos poucos estudos ${ }^{7}$ empíricos existentes sobre custo de ajustamento em integrações comerciais. (Greenaway e Hine, 1991).

\section{VANTAGENS COMPARATIVAS E CUSTOS DE AJUSTAMENTO EM INTEGRAÇÃO REGIO- NAL DE COMÉRCIO}

Do ponto de vista da metodologia adotada no presente artigo, resta ainda uma questão a ser esclarecida: como podemos utilizar os resultados da literatura econômica, explicitados na seção anterior, no presente estudo? Em primeiro lugar, a análise aqui efetuada está baseada na identificação das vantagens comparativas (reveladas) dos países. Assim sendo, os resultados acima mencionados precisam ser adaptados ao contexto do padrão de vantagens comparativas dos países. Uma integração comercial que liberaliza o comércio entre dois países quaisquer levará a diferentes padrões de comércio intrabloco, dependendo se o padrão de vantagens comparativas ex-ante é "similar" ou "distinto" (a definição do grau de similaridade será apresentada mais adiante). Se o padrão de vantagens comparativas for significativamente distinto, ou seja, se um dos países tiver vantagem comparativa em computadores e o outro em têxteis, então é plausível admitir-se que a liberalização comercial intrabloco levará a uma expansão de comércio predominantemente do tipo interindústria. E, em correspondência, em cada um dos países há uma expressiva reestruturação das atividades produtivas segundo as vantagens comparativas. Ou seja, há um ajuste nessas economias próximo do tipo previsto no modelo Heckscher-Ohlin. Portanto, se o padrão de vantagens comparativas for significativamente distinto, então uma liberalização comercial intrabloco tenderá a estar associada a um alto custo de ajustamento setorial nos países. Por outro lado, se o padrão de vantagens comparativas ex-ante for similar, a liberalização comercial intrabloco tenderá a induzir um comércio intrabloco próximo do caráter intra-indústria, pois ambos os países possuem vantagens comparativas reveladas nos "mesmos" tipos de indústrias e setores. Uma integração comercial nesse segundo caso teria relativamente um menor custo de ajustamento setorial nos países. Em suma, no artigo assumiremos que a integração comercial entre países com similaridade do padrão de VCR tem relativamente um menor custo econômico de ajustamento setorial do que ocorre no caso de dissimilaridade.

O grau de similaridade do padrão de vantagens comparativas também permite um outro tipo de conjetura, ainda que bastante condicionada. Numa negociação comercial entre um país grande e um grupo de países pequenos há uma assimetria de poder. Assim sendo, se os países pequenos atuarem conjuntamente na negociação comercial poderão, em princípio, obter maiores ganhos conjuntos (e, provavelmente, individuais), porque a atuação conjunta aumenta o poder de barganha do

7 Ver Adler (1970) e Fukurora (1990). 
grupo como um todo ${ }^{8}$ ante o país grande. Entretanto, uma condição óbvia necessária, para haver viabilidade de atuação conjunta desses países pequenos, é a exigência de estes terem interesses comuns, ou similares, isto é, atuarem nos mesmos mercados de produtos de exportação. Assim sendo, a similaridade do padrão de vantagens comparativas dos países também pode, eventualmente, sugerir a existência potencial de condições para a conjugação de interesses de países ("pequenos”) numa negociação comercial com um país grande. Portanto, a partir da similaridade do padrão de VCR também efetuaremos uma conjetura adicional, qual seja, a possibilidade de uma atuação conjunta de países sul-americanos nas negociações da ALCA, mesmo considerando as fortes restrições já apontadas (ver nota de rodapé 8).

Em suma, a análise de vantagens comparativas e suas implicações para os custos de integração comercial entre países é, antes, sugestiva e indireta, do que uma mensuração direta dessa questão. E, até com mais severas limitações, o mesmo pode ser dito a respeito do incentivo que os países têm para uma atuação conjunta nas negociações da ALCA. Todavia, na resposta a esses dois tipos de questões, a informação gerada pela identificação do grau de similaridade do padrão de vantagens comparativas entre países é uma informação adicional, útil e plausível e, como veremos, produz resultados de acordo com o que se observou nas negociações realizadas.

\section{SIMILARIDADE DA PAUTA DE EXPORTAÇÃO DOS PAÍSES}

Na seção 3 foi analisado o padrão de vantagens comparativas de 11 dos 12 países americanos considerados neste estudo. No entanto, não investigamos quão similares (ou dissimilares) são esses países. Conforme expusemos nas seções 4 e 5, esta questão é crucial para se intuir até que ponto um acordo comercial que liberalize o comércio entre eles irá ou não impor grandes ajustes às suas economias domésticas. A similaridade do padrão de exportação dos países tem sido tratada na literatura de duas formas: (1) mediante a mensuração da similaridade da pauta de exportações e (2) por meio da mensuração da similaridade do padrão de vantagens comparativas (reveladas). A primeira medida, que é coberta nesta seção, consiste da utilização do índice de similaridade de exportações de Finger e Kreinin (1979). Este índice é definido como medida de similaridade de exportações de quaisquer dois países destinadas ao mercado mundial ou a um terceiro mercado específico e cuja expressão é a seguinte: ${ }^{9}$

$$
S(a b, c)=\left\{\sum_{i} \operatorname{Min}\left[X_{i}(a, c), X_{i}(b, c)\right]\right\} .100
$$

8 A literatura (Fudenberg e Tirole, 1991) aponta muitas condições que precisam ser satisfeitas para que seja efetivo um determinado acordo de atuação conjunta entre um grupo de agentes. Entre as condições necessárias há, por exemplo, limitações do número de agentes envolvidos, existência de capacidade de fiscalização e de imposição das regras acordadas, limitações sobre a magnitude dos ganhos individuais que determinado agente obtém ao romper o acordo ou atuar como "free rider", e assim por diante. No presente caso, que envolve países e, portanto, com atuação em vários mercados de exportação, analisamos apenas uma condição óbvia entre as muitas necessárias para inferir sobre a possibilidade da atuação em conjunto de um grupo de agentes ("países pequenos") numa negociação comercial, qual seja, da "igualdade" ou "similaridade” de interesses. Isto é, em primeiro lugar esses agentes ("países") devem ter um interesse comum de busca de maximização de lucros nos "mesmos" mercados ou produtos de exportação. Mas, pelo fato de as condições para a efetiva atuação em conjunto na exploração ("oligopolística") desses mercados de exportação serem múltiplas e complexas, sendo que neste trabalho destacamos apenas uma, os resultados aqui obtidos serão decididamente precários. A despeito disso, uma conjetura sobre em qual grupo de países pequenos é que há, em princípio, um interesse comum, é pertinente. Isto porque, nesse grupo de países com igualdade ou conjugação de interesses (i.e., de atuação nos mesmos mercados) é que, em princípio, pode surgir mais naturalmente um acordo para uma atuação em conjunto numa negociação comercial visando a um ganho maior (global e individual) na "exploração" de mercados do país grande. Evidentemente, esse tipo de atuação em grupo de países (pequenos) é problemático, com equilíbrio instável e sempre sujeito a defecções entre os parceiros do acordo, principalmente se as condições para uma atuação efetiva em grupo não forem adequadamente preenchidas.

9 Ver também em Greenaway e Milner (1993); ou em Kellman e Schroder (1983) e em Pomfret (1981). 
onde $\mathrm{X}_{\mathrm{i}}$ é a proporção das exportações de cada setor nas exportações totais de cada país considerado ("a" ou "b"), sendo "c" o mercado de destino de referência (no artigo: mundo) dos dois países em foco. O valor do índice é obtido por meio da soma das menores participações em cada setor nos dois países. Os resultados possíveis variam de 0 (total dissimilaridade) a 100 (total similaridade). No presente estudo, calculamos o índice de similaridade de exportações para cada um dos três anos do último subperíodo amostral, ${ }^{10}$ nas várias combinações possíveis de dois países entre o total de 11 países americanos aqui considerados (sem o Brasil). A Tabela 3 reporta a média dos valores anuais desse índice para o subperíodo final considerado. Assim, por exemplo, o índice de similaridade de exportações (média de 1997-1999) entre a Argentina e a Bolívia foi de 60, entre a Argentina e o Chile foi de 37, entre a Bolívia e o Chile foi de 42 etc...

O critério de similaridade assumido por Finger e Kreinin (1979) é um valor desse índice igual ou maior do que 50 e, neste caso, a Tabela 3 revela o seguinte:

(1) Os 11 países podem ser agrupados em 3 grupos completamente distintos;

(2) Há o grupo 1, formado pelos países do NAFTA (México, EUA e Canadá), para os quais o valor do índice de similaridade entre esses países é sempre superior a 50, ou seja, são países similares na sua pauta de exportações no subperíodo final;

(3) Há o grupo 2, formado por alguns dos países da América do Sul aqui considerados, sendo constituído por Argentina, Bolívia, Colômbia, Equador, Peru e Uruguai. No caso destes países, o índice de similaridade entre os mesmos é quase sempre superior a 50. Portanto, quanto à pauta de exportações esses países são similares entre si no subperíodo final. As únicas duas exceções são os índices de Argentina-Peru (valor 44) e Bolívia-Colômbia (valor 49), ou seja, mesmo nesses casos de exceção o índice é elevado e quase satisfaz o critério de similaridade;

(4) Há o grupo 3, também formado por países da América do Sul, sendo constituído pelo Chile e Venezuela. A este grupo 3 podemos chamar de grupo de países diferenciados, isolados, ou independentes, pois o índice de similaridade entre eles e com os outros países aqui considerados é quase sempre menor do que 50, e muitas vezes de valor bastante reduzido. Ou seja, no que diz respeito à pauta de exportações esses dois países são dissimilares entre si e dissimilares com os outros países aqui considerados. A única exceção a esse padrão constitui o índice entre ChilePeru, cujo valor 67 é elevado e satisfaz ao critério de similaridade;

(5) O grau de similaridade da pauta de exportações entre países de grupos distintos, isto é, entre países do grupo 1 e 2, do grupo 1 e 3 e do grupo 2 e 3, sempre é menor do que 50, muitas vezes de valor bastante reduzido. Assim, quanto à pauta de exportações tem-se que países de grupos distintos são dissimilares entre si.

Em suma, no que diz respeito à pauta de exportações no subperíodo 1997-1999, os 11 países aqui considerados podem ser agrupados em três grupos distintos. Esses grupos são dissimilares entre si e, portanto, uma integração comercial entre os mesmos dinamizaria um comércio tipo interindústria. Isto implica que uma liberalização do comércio entre países desses grupos distintos tem um relativo maior custo econômico de ajustamento setorial. Além disso, numa negociação comercial que envolva os países componentes do grupo 1 e do grupo 2, pelo índice de similaridade de exportações resulta que cada grupo tem um incentivo natural para atuar de modo conjunto, respectivamente como grupo 1 e como grupo 2. Isto porque, os países em cada um desses dois grupos são "bastante" similares entre si e, portanto, têm interesses comerciais comuns. Os países do grupo

10 Efetuamos o cálculo do índice Finger e Kreinin somente para último subperíodo, porque, em primeiro lugar, esse índice é considerado apenas uma indicação preliminar sobre as duas questões do presente artigo e o cálculo do índice não se baseia no foco central do mesmo, qual seja, de identificação do padrão de VCR dos países e das suas conseqüências. Em segundo lugar, porque é talvez o período mais atual nessa base de dados para a percepção contemporânea dos países sobre essas duas questões. 
3 (Chile e Venezuela), porque são dissimilares entre si e com todos os outros países, tenderiam a atuar de modo isolado, independente e autocentrado numa negociação comercial que englobe os 11 países aqui considerados.

Tabela 3 - Índice Finger \& Kreinin - Média anual do subperíodo 1997-1999

\begin{tabular}{|c|c|c|c|c|c|c|}
\hline & ARGENTINA & BOLIVIA & CHILE & COLÔMBIA & EQUADOR & PERU \\
\hline ARGENTINA & XXXXX & 60 & 37 & 68 & 70 & 44 \\
\hline BOLIVIA & 60 & $x x x x x$ & 42 & 49 & 57 & 53 \\
\hline CHILE & 37 & 42 & XXXXXX & 36 & 35 & 61 \\
\hline COLÔMBIA & 68 & 49 & 36 & $X X X X X$ & 67 & 52 \\
\hline EQUADOR & 70 & 57 & 35 & 67 & $X X X X X$ & 52 \\
\hline PERU & 44 & 53 & 61 & 52 & 52 & XXXXX \\
\hline URUGUAI & 70 & 52 & 34 & 68 & 64 & 51 \\
\hline VENEZUELA & 35 & 25 & 36 & 40 & 32 & 31 \\
\hline MÉXICO & 42 & 37 & 30 & 36 & 30 & 25 \\
\hline EUA & 49 & 36 & 29 & 41 & 33 & 23 \\
\hline \multirow[t]{2}{*}{ CANADÁ } & 46 & 48 & 41 & 36 & 35 & 25 \\
\hline & URUGUAI & VENEZUELA & & & EUA & CANADÁ \\
\hline ARGENTINA & 70 & 35 & & & 49 & 46 \\
\hline BOLÍVIA & 52 & 25 & & & 36 & 48 \\
\hline CHILE & 34 & 36 & & & 29 & 41 \\
\hline COLÔMBIA & 68 & 40 & & & 41 & 36 \\
\hline EQUADOR & 64 & 32 & & & 33 & 35 \\
\hline PERU & 51 & 31 & & & 23 & 25 \\
\hline URUGUAI & $X X X X X$ & 25 & & & 30 & 27 \\
\hline VENEZUELA & 25 & $X X X X X$ & & & 33 & 34 \\
\hline MÉXICO & 30 & 26 & & & 78 & 63 \\
\hline EUA & 30 & 33 & & & $X X X X X$ & 68 \\
\hline CANADÁ & 27 & 34 & & & 68 & $X X X X X$ \\
\hline
\end{tabular}

\section{Similaridade E AGRUPamentos Naturais de PaÍses}

Uma segunda medida de similaridade considerada na literatura - ver Lee (1995), Kreinin e Plummer (1994), Chow (1990) e Rana (1990) - consiste do cômputo do coeficiente de correlação de Spearman, ou correlação com ordenação ("rank-correlation"), entre os padrões de VCR de dois países. Este coeficiente de correlação (que varia entre -1 e +1 ) é uma medida não-paramétrica, que mostra como duas séries ordenadas de dados estão correlacionadas. No presente caso, a ordenação é dada pelos 31 setores manufatureiros. Portanto, a medida da correlação de Spearman estará verificando como os vetores com os valores dos índices de vantagens comparativas (ordenados segundo esses 31 setores) estão correlacionados entre dois países. Evidentemente, se dois países têm elevado coeficiente de correlação positivo entre os seus respectivos vetores (ou padrão) de vantagem comparativa revelada, isto indica que esses dois países são similares. E se dois países têm baixo ou negativo coeficiente de correlação Spearman, então esses dois países apresentam vantagens comparativas reveladas em setores distintos um do outro e, portanto, são países dissimilares entre si. Tendo em vista isto, calculamos o coeficiente de correlação de Spearman entre os padrões de VCR para todas as combinações possíveis de dois países entre os 11 aqui considerados. ${ }^{11}$ A Tabela 4 reporta os va-

11 No anexo 2 efetuamos a análise de correlações Spearman entre padrões de VCR de países das Américas com inclusão do Brasil no conjunto de países das Américas, perfazendo um total de 12 países. Nas considerações finais (seção 8) efetuamos a análise conjunta dos resultados de todos os países das Américas, incluindo-se os resultados obtidos para o Brasil no anexo 2. 
lores do coeficiente de correlação Spearman para os quatro subperíodos relativos aos anos 1990. A análise com respeito à similaridade existente entre os 11 países aqui considerados será efetuada com base nos valores da correlação Spearman ${ }^{12}$ constantes desta Tabela 4.

Tabela 4

\begin{tabular}{|c|c|c|c|c|c|c|c|c|c|c|c|c|}
\hline & \multicolumn{4}{|c|}{ ARGENTINA } & \multicolumn{4}{|c|}{ BOLÍVIA } & \multicolumn{4}{|c|}{ CHILE } \\
\hline & $90-92$ & 93-95 & 96-98 & $97-99$ & $90-92$ & 93-95 & $96-98$ & $97-99$ & $90-92$ & 93-95 & 96-98 & $97-99$ \\
\hline ARGENTINA & $X X X$ & $\mathrm{XXX}$ & $X X X$ & $X X X$ & $0,28^{*}$ & $0,34^{*}$ & 0,16 & 0,09 & $0,47^{*}$ & $0,33^{*}$ & $0,48^{*}$ & $0,56^{*}$ \\
\hline BOLÍVIA & $0,28^{*}$ & & & & $X X X$ & $X X X$ & $x x x$ & $x x x$ & $0,28^{*}$ & $-0,05$ & $0,33^{*}$ & $0,30^{*}$ \\
\hline CHILE & $0,47^{*}$ & $0,33^{*}$ & $0,48^{*}$ & $0,56^{*}$ & $0,28^{*}$ & $-0,05$ & $0,33^{*}$ & $0,30^{*}$ & $x x x$ & $x X X$ & $x x x$ & $x x x$ \\
\hline & $0,58^{*}$ & 0,62 & & $0,44^{*}$ & $0,32^{*}$ & $0,36^{*}$ & & $-0,07$ & $0,23^{*}$ & & $0,26^{*}$ & $0,29^{*}$ \\
\hline & & & & & $0,30^{*}$ & $0,38^{*}$ & & $0,29^{*}$ & $0,41^{*}$ & $0,34^{*}$ & $0,38^{*}$ & $0,42^{*}$ \\
\hline PE & $0,51^{*}$ & & 0 & & $0,24^{*}$ & $0,26^{*}$ & & & $0,40^{*}$ & & $0,42^{*}$ & $0,47^{*}$ \\
\hline & $52^{*}$ & & 0 & & $45^{*}$ & $0,50^{*}$ & 0,3 & 0,3 & $9^{*}$ & & $0,39^{*}$ & $0,37^{*}$ \\
\hline & 0, & 0,2 & 0,4 & & $-0,09$ & $-0,04$ & 0 & -0 & $0,37^{*}$ & 0 & $0,35^{*}$ & 0, \\
\hline & 0,5 & & $-0,3$ & $-0,4$ & & 0,08 & & & & & & $-0,3$ \\
\hline & $-0,22^{*}$ & $-0,28^{*}$ & $-0,28^{*}$ & $-0,21$ & $-0,06$ & $-0,16$ & $-0,27^{*}$ & $-0,2$ & $-0,26^{*}$ & $-0,20^{*}$ & $-0,31^{*}$ & $-0,26^{*}$ \\
\hline \multirow[t]{3}{*}{ CANADÁ } & $-0,07$ & $-0,02$ & $0,25^{*}$ & 0,23 & $-0,17$ & $-0,26^{*}$ & 0,01 & 0,0 & 0,32 & $0,37^{*}$ & $0,52^{*}$ & $0,53^{*}$ \\
\hline & \multicolumn{4}{|c|}{ COLÔMBIA } & \multicolumn{4}{|c|}{ EQUADOR } & \multicolumn{4}{|c|}{ PERU } \\
\hline & $90-92$ & 93-95 & $96-98$ & $97-99$ & $90-92$ & 93-95 & $96-98$ & $97-99$ & $90-92$ & 93-95 & $96-98$ & $97-99$ \\
\hline AR & $0,58^{*}$ & $0,62^{*}$ & 0,4 & $0,44^{*}$ & 0,17 & $\begin{array}{l}0,14 \\
038^{*}\end{array}$ & $0,24^{*}$ & $0,20^{*}$ & $0,51^{*}$ & $0,42^{*}$ & & $0,20^{*}$ \\
\hline & & & $\begin{array}{l}0,0 \\
0,2\end{array}$ & & & $\begin{array}{l}0,38^{*} \\
0,34^{*}\end{array}$ & & $\begin{array}{l}0,29^{*} \\
0,42^{*}\end{array}$ & & & $\begin{array}{l}0,46^{*} \\
0,42^{*}\end{array}$ & $\begin{array}{l}0,40^{*} \\
0,47^{*}\end{array}$ \\
\hline MBIA & $X X X$ & & & & $0,29^{*}$ & $0,51^{*}$ & $0,47^{*}$ & $0,49^{*}$ & $0,44^{*}$ & 0,6 & $0,49^{*}$ & $0,51^{*}$ \\
\hline ADOR & $0,29^{*}$ & $0,51^{*}$ & $0,47^{*}$ & $0,49^{*}$ & $X X X$ & $x X X$ & $X X X$ & $X X X$ & $0,52^{*}$ & $0,69^{*}$ & $0,71^{*}$ & $0,69^{*}$ \\
\hline PEF & $0,44^{*}$ & $0,65^{*}$ & 0,4 & 0,5 & $0,52^{*}$ & $0,69^{*}$ & $0,71^{*}$ & $0,69^{*}$ & $X X X$ & $X X X$ & $X X X$ & $x X X$ \\
\hline \multirow{7}{*}{$\begin{array}{l}\text { URUGUAI } \\
\text { VENEZUELA } \\
\text { MÉXICO } \\
\text { EUA } \\
\text { CANADÁ }\end{array}$} & $0,55^{*}$ & $0,62^{*}$ & 0,4 & $0,50^{*}$ & $0,25^{*}$ & $0,45^{*}$ & 0,3 & $0,44^{*}$ & $0,41^{*}$ & & & \\
\hline & $0,29^{*}$ & $0,35^{*}$ & $0,28^{*}$ & $0,34^{*}$ & $0,20^{*}$ & $0,35^{*}$ & $0,27^{*}$ & $0,28^{*}$ & $0,27^{*}$ & $0,33^{*}$ & 0,2 & \\
\hline & 0,13 & $0,30^{*}$ & $-0,11$ & $-0,14$ & $0,24^{*}$ & $0,25^{\star}$ & $-0,10$ & $-0,09$ & $0,43^{*}$ & $0,47^{*}$ & & $-0,17$ \\
\hline & & $-0,28^{*}$ & & $0030^{*}$ & -0.07 & $-0,12$ & $-0,3$ & $-0,3$ & $-0,22^{*}$ & $-0,39^{*}$ & $5^{*}$ & $-0,33^{*}$ \\
\hline & & & & & & & & & & & & \\
\hline & \multicolumn{4}{|c|}{ URUGUAI } & \multicolumn{4}{|c|}{ VENEZUELA } & \multicolumn{4}{|c|}{ MÉXICO } \\
\hline & $90-92$ & 93-95 & $96-98$ & $97-99$ & $90-92$ & 93-95 & $96-98$ & $97-99$ & $90-92$ & 93-95 & $96-98$ & $97-99$ \\
\hline & $0,52^{*}$ & $0,44^{*}$ & $0,40^{*}$ & $0,39^{*}$ & $0,43^{*}$ & $0,41^{*}$ & $0,48^{*}$ & $0,53^{*}$ & $0,56^{*}$ & $0,53^{*}$ & $-0,38^{*}$ & $-0,49^{*}$ \\
\hline & & & & & & & & & & & & \\
\hline & 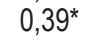 & & 0,3 & & $0,37^{*}$ & $0,26^{*}$ & & & $2^{*}$ & & -0 & \\
\hline COLOMBIA & $0,55^{*}$ & $0,62^{*}$ & $0,47^{*}$ & 0,50 & $0,29^{*}$ & $0,35^{*}$ & 0,2 & $0,34^{*}$ & 0,1 & & -0 & -0, \\
\hline & $0,25^{*}$ & $0,45^{*}$ & & & $0,20^{*}$ & & & & & & & \\
\hline & & & & & $0,27^{*}$ & & & & & & & \\
\hline URUGUAI & $X X X$ & $X X X$ & & $x x x$ & $0,38^{*}$ & $0,20^{*}$ & $0,31^{*}$ & $0,29^{*}$ & $0,33^{*}$ & $0,35^{*}$ & $-0,05$ & $-0,04$ \\
\hline VENEZUELA & $0,38^{*}$ & 0,2 & 0,3 & $0,29^{*}$ & $X X X$ & $X X X$ & & $X X X$ & $0,47^{*}$ & $0,69^{*}$ & $-0,30^{*}$ & $-0,38^{*}$ \\
\hline & & & & & $0,47^{*}$ & $0,69^{*}$ & $-0,30^{*}$ & $-0,38^{*}$ & $x x x$ & & XXX & \\
\hline EUA & $-0,47^{*}$ & $-0,52^{*}$ & $-0,51^{*}$ & $-0,51^{*}$ & $-0,12$ & $-0,12$ & $-0,19^{*}$ & $-0,14$ & $-0,35^{*}$ & $-0,36^{*}$ & $-0,22^{*}$ & $-0,21^{*}$ \\
\hline CANADÁ & $-0,45^{*}$ & $-0,32^{*}$ & $-0,36^{*}$ & $-0,33^{*}$ & $-0,15$ & $0,19^{*}$ & 0,13 & 0,14 & 0,05 & 0,03 & $-0,25^{*}$ & $-0,25^{*}$ \\
\hline
\end{tabular}

$12 \mathrm{O}$ asterisco indica que no teste de hipóteses unicaudal a hipótese $\mathrm{H}_{0}$ é rejeitada em até $5 \%$ de nível de significância respectivamente para as correlações positivas e para as negativas. 
Tabela 4 (cont.)

\begin{tabular}{|c|c|c|c|c|c|c|c|c|}
\hline & \multicolumn{4}{|c|}{ ESTADOS UNIDOS (EUA) } & \multicolumn{4}{|c|}{ CANADÁ } \\
\hline & $90-92$ & $93-95$ & $96-98$ & $97-99$ & $90-92$ & $93-95$ & $96-98$ & $97-99$ \\
\hline ARGENTINA & $-0,22^{*}$ & $-0,28^{*}$ & $-0,28^{*}$ & $-0,21^{*}$ & $-0,07$ & $-0,02$ & $0,25^{*}$ & $0,23^{*}$ \\
\hline BOLÍVIA & $-0,06$ & $-0,16$ & $-0,27^{*}$ & $-0,23^{*}$ & $-0,17$ & $-0,26^{*}$ & 0,01 & 0,05 \\
\hline CHILE & $-0,26^{*}$ & $-0,20^{*}$ & $-0,31^{*}$ & $-0,26^{*}$ & $0,32^{*}$ & $0,37^{*}$ & $0,52^{*}$ & $0,53^{*}$ \\
\hline COLOMBIA & $-0,29 *$ & $-0,28^{*}$ & $-0,43^{*}$ & $-0,39^{*}$ & $-0,37^{*}$ & $-0,25^{*}$ & $-0,11$ & $-0,14$ \\
\hline EQUADOR & $-0,07$ & $-0,12$ & $-0,32^{*}$ & $-0,37^{*}$ & $-0,03$ & 0,01 & 0,13 & 0,11 \\
\hline PERU & $-0,22^{*}$ & $-0,39 *$ & $-0,35^{*}$ & $-0,33^{*}$ & $-0,17$ & $-0,10$ & $-0,02$ & $-0,02$ \\
\hline URUGUAI & $-0,47^{*}$ & $-0,52^{*}$ & $-0,51^{*}$ & $-0,51^{*}$ & $-0,45^{*}$ & $-0,32^{*}$ & $-0,36^{*}$ & $-0,33^{*}$ \\
\hline VENEZUELA & $-0,12$ & $-0,12$ & $-0,19^{*}$ & $-0,14$ & $-0,15$ & $0,19^{*}$ & 0,13 & 0,14 \\
\hline MÉXICO & $-0,35^{*}$ & $-0,36^{*}$ & $-0,22^{*}$ & $-0,21^{*}$ & 0,05 & 0,03 & $-0,25^{*}$ & $-0,25^{*}$ \\
\hline EUA & $X X X$ & $X X X$ & $X X X$ & $X X X$ & 0,15 & $0,18^{*}$ & 0,17 & 0,16 \\
\hline CANADÁ & 0,15 & $0,18^{*}$ & 0,17 & 0,16 & $X X X$ & $X X X$ & $X X X$ & $X X X$ \\
\hline
\end{tabular}

O aspecto inicial a ser ressaltado é que, de modo geral, os resultados revelados pelo coeficiente de correlação de Spearman estão em sintonia com aqueles revelados pelo índice de Finger e Kreinin. Mas há algumas diferenças. As principais características reveladas pelo coeficiente de correlação $^{13}$ são as seguintes:

(1) O aspecto mais marcante é o de que o coeficiente de correlação entre os Estados Unidos e os países latino-americanos é negativo (estatisticamente significativo) na grande maioria dos casos e subperíodos (mesmo nos anos 1980), ao passo que o coeficiente de correlação entre EUA e Canadá não é estatisticamente significativo (i.e., não há correlação), exceto para o subperíodo 1993-1995;

(2) O coeficiente de correlação entre o Canadá e os países latino-americanos não é estatisticamente significativo. A única exceção é a correlação Canadá-Chile, que é positiva e estatisticamente significante, e ao final do período é elevada;

(3) As correlações entre os países sul-americanos são, na sua ampla maioria, positivas e estatisticamente significativas. No caso da Argentina, Colômbia, Equador, Peru e Uruguai as correlações entre eles são, em geral, de valores médios a elevados, enquanto que no caso da Bolívia e Venezuela as correlações são em geral baixas com os demais países, exceto para os casos Bolívia-Uruguai e Venezuela-Argentina. O caso do Chile é um pouco diferenciado, pois apresenta correlações baixas, médias e elevadas com os demais países sul-americanos;

(4) O caso do México é bastante especial. Este país apresenta correlações positivas, em muitos casos de valor médio e elevado, com os demais países latino-americanos até o subperíodo 1993-1995. Mas nos dois subperíodos finais o coeficiente apresenta uma reversão e passa a ser negativo com esses países. Para o caso México-EUA, no entanto, mesmo nos subperíodos finais não há uma reversão (oposta) do sinal do coeficiente, pois o mesmo continua negativo (embora, talvez, com tendência à redução da dissimilaridade), e para o caso México-Canadá aumenta-se a diferenciação (dissimilaridade) entre eles - pois o coeficiente passa de não significante para negativobaixo e significativo.

Assim sendo, o quadro retratado na Tabela 4 apresenta, com algumas pequenas diferenças, muitos dos resultados obtidos no caso do índice Finger e Kreinin. Primeiramente, os países do

$13 \mathrm{Na}$ análise adotamos o seguinte critério: a rejeição da hipótese $\mathrm{H}_{0}$ ocorre quando, no mínimo, no caso de valores positivos, o valor do coeficiente estimado de correlação é maior do que um valor ao redor de 0,180 (e valor crítico: 0,177; EUA-Canadá: 93-95). Por isso, consideramos como valor "baixo" quando o coeficiente está entre $[0,180$ e 0,360], valor "médio" entre [0,360 e 0,540$]$ e valor "elevado" quando o coeficiente for maior do que 0,540 . O mesmo critério se aplica para os valores negativos da correlação. 
NAFTA (EUA, Canadá e México) têm, ao final de período (pós-1995), um coeficiente de correlação Spearman com os demais países aqui considerados que mostra que estes são dissimilares com os demais países (sul-americanos). Este resultado fundamental também foi obtido no caso do índice Finger e Kreinin. Portanto, uma integração comercial entre os países do NAFTA com os demais países aqui considerados (sul-americanos) tem um relativamente maior custo econômico de integração comercial. E mesmo que se considere que o coeficiente de correlação Spearman, ao contrário do índice Finger e Kreinin, indica que os países do NAFTA também são dissimilares entre si, isto não se constitui num problema. Isto porque, esses países já se constituem num bloco regional de comércio e, como tal, tendem a atuar conjuntamente nas negociações da ALCA.

Em segundo lugar, com relação ao conjunto de países que formam um grupo de países similares entre si e que, portanto, têm um incentivo natural (devido à conjugação dos interesses comerciais) para uma atuação conjunta nas negociações da ALCA, os resultados expostos na Tabela 4 não são tão imediatos quanto o foram no caso do índice Finger e Kreinin. A definição desse grupo entre os países sul-americanos necessita de critérios de escolha adicionais. Os critérios adicionais estabelecidos foram, primeiramente, o de escolher as correlações (desde que sempre positivas nos anos 1990) entre os padrões de VCR que tivessem um coeficiente de valor entre médio e elevado. Esse primeiro critério mostra todos os possíveis casos de padrões de VCR que sejam similares entre dois países, em qualquer um dos quatro subperíodos dos anos 1990. Além desse critério, procuramos escolher, entre as correlações resultantes do primeiro critério, aquelas correlações que se mantiveram entre médio e elevado por pelo menos três dos quatro subperíodos nos anos 1990, com a particularidade de que pelo menos um deles seja de valor elevado. Em suma, buscou-se escolher aquelas correlações entre os padrões de VCR que fossem "fortes e estáveis" ao longo de todos os anos 1990 e não só no subperíodo final. Essas correlações estão explicitadas na Tabela 5, e desse conjunto de países definimos o grupo de países similares entre si.

\section{Tabela 5 - Correlação Spearman “forte e estável” entre padrões de VCR de países das Américas ao longo dos anos 1990}

\begin{tabular}{llll}
\hline Argentina-Chile & Argentina-Venezuela & Chile-Canadá & Colômbia-Uruguai \\
Argentina-Colômbia & Bolívia-Uruguai & Colômbia-Equador & Equador-Peru \\
Argentina-Uruguai & Chile-Peru & Colômbia-Peru & Peru-Uruguai \\
\hline
\end{tabular}

Portanto, os países candidatos a formarem o grupo de países similares entre si são os seguintes: ${ }^{14}$ Argentina (4), Bolívia (1), Canadá (1), Chile (3), Colômbia (4), Equador (2), Peru (4), Uruguai (4) e Venezuela (1). No entanto, como se exige que a similaridade do padrão de VCR entre o grupo de países similares seja forte e estável entre todos eles, primeiramente descartou-se a Bolívia, o Canadá e a Venezuela, pois esses países têm somente um caso de similaridade forte e estável com algum outro país desse conjunto de escolha, mas não o têm com a grande maioria dos países desse conjunto. O segundo conjunto resultante dessa exclusão consiste então dos seguintes países: Argentina (3), Chile (2), Colômbia (4), Equador (2), Peru (4) e Uruguai (3). Novamente, a exclusão dos países com o menor número de similaridade do padrão de VCR com países desse segundo conjunto, isto é, descartando-se o Chile e o Equador, resulta no seguinte grupo final de países: Argentina (2) Colômbia (3), Peru (2) e Uruguai (3). Este último grupo satisfaz o critério de que, de um total de três relações possíveis entre padrões de VCR para cada um desses países, cada um deles tem pelo

14 O número entre parênteses mostra com quantos outros países desse conjunto um determinado país tem relações de similaridade ("forte e estável") com respeito aos respectivos padrões de VCR. Assim, por exemplo, a Argentina tem relações de similaridade de padrão de VCR com outros quatro países: Chile, Colômbia, Uruguai e Venezuela. 
menos 2/3 de correlações fortes e estáveis de padrões de VCR entre os países desse grupo final. Isto é, cada um desses países apresenta similaridade (forte e estável) entre os respectivos padrões de VCR com quase ou com a totalidade dos países desse grupo final. Portanto, esse grupo final constitui-se efetivamente de um grupo de países similares entre si. E numa interpretação de Kreinin e Plummer (1994), um grupo desse tipo forma um "bloco natural” de países, no sentido de que a introdução do país ao bloco não altera o seu padrão de vantagens comparativas e nem o do bloco, pois todos têm o "mesmo" padrão de VCR.

Em suma, com a utilização do coeficiente de correlação de Spearman estabeleceu-se o grau de associação entre os padrões de VCR de 11 países das Américas aqui considerados. A análise desse coeficiente nos anos 1990 revela que os EUA, o Canadá e o México (este último, somente após 1995) são dissimilares com relação ao padrão de VCR dos demais países (sul-americanos) aqui considerados. Portanto, uma integração comercial que liberalize o comércio entre os países do NAFTA e os países sul-americanos aqui considerados tenderá a promover um comércio tipo interindústria entre eles e, assim, haverá um relativo maior custo econômico de integração comercial. Não há também similaridade dos padrões de VCR entre os países do NAFTA, embora pareça haver certa convergência do México para os EUA, ou, pelo menos, uma redução da dissimilaridade inicial entre eles. Em correspondência, há igualmente um substantivo distanciamento (crescente dissimilaridade) do México com os demais países sul-americanos aqui considerados. Entre estes, há quatro países, a saber, Argentina, Colômbia, Peru e Uruguai, que apresentam forte e estável similaridade entre seus respectivos padrões de VCR ao longo do tempo, formando, assim, um "bloco natural" de países. Esses quatro países, portanto, pela conjugação dos interesses comerciais, têm um incentivo natural para atuar de modo conjunto, coordenado e sistemático nas negociações da ALCA. Os países sul-americanos que não apresentam similaridade (forte e estável) com os demais países da América do Sul, ou com os países do NAFTA são, em grau crescente de dissimilaridade, o Equador, o Chile, a Bolívia e a Venezuela. Portanto, por esse critério, estes países teriam incentivos para atuar de modo isolado, independente e autocentrado nas negociações da ALCA, pelo menos aqueles com maior grau de dissimilaridade (Venezuela, Bolívia e Chile). Assim, neste aspecto há também uma pequena diferença com relação ao índice Finger e Kreinin, pois segundo este critério tanto a Bolívia quanto o Equador faziam parte do grupo de países similares entre si. Porém, pelo critério de correlação de Spearman, a Bolívia decididamente não faz parte do grupo de países similares entre si, enquanto que no caso do Equador é mais questionável a sua não inclusão nesse grupo, pois constitui um caso limítrofe no critério de correlação de Spearman.

\section{CONSIDERAÇÕES FINAIS}

Nos dois critérios de similaridade analisados, constatamos que uma integração regional de comércio que liberalize o comércio entre os países do NAFTA e os países sul-americanos aqui considerados, porque são conjuntos de países dissimilares, tem um relativo maior custo econômico de integração comercial. Este resultado se aplica também ao Brasil (ver anexo 2), o qual é dissimilar com todos os países aqui considerados. Neste sentido, e do ponto de vista do padrão de VCR, todos os países sul-americanos aqui analisados (incluso o Brasil) teriam, em princípio, simpatia pela opção de uma ALCA "light”. A razão disto é que, em tese, essa concepção "light”, ao contrário de uma concepção "hard" (com imediata e ampla liberalização intrabloco), permite uma melhor compatibilização com as contrapressões domésticas que são geradas pela perspectiva do maior custo econômico de ajustamento setorial imposto às economias domésticas na ALCA. Entretanto, como nem todos os países sul-americanos são similares entre si, e como a perspectiva de acesso a um 
mercado do tamanho do NAFTA é uma persuasão considerável, decididamente abre-se espaço para comportamentos distintos entre os países sul-americanos. Ou seja, em termos da análise aqui efetuada é a dissimilaridade entre conjuntos de países sul-americanos e não é a existência de diferentes custos de integração comercial - pois os mesmos são relativamente elevados para todos os países sul-americanos numa integração comercial com o NAFTA - que explica posturas diferenciadas de grupos desses países nas negociações da ALCA.

Em segundo lugar, há somente um subconjunto dos países sul-americanos aqui considerados, a saber, a Argentina, a Colômbia, o Peru, o Uruguai e, talvez, o Equador, que constitui um grupo de países similares entre si ("bloco natural de países”). Note-se que esse mesmo grupo de países resulta também ser um "bloco natural de países” quando adotamos uma classificação ligeiramente diferenciada para permitir certa compatibilização entre classificação ISIC (UNIDO) e NCM (Brasil) e, assim, possibilitar a inclusão do Brasil no conjunto de países analisados em termos de similaridade do padrão de VCR (ver Anexo 2). Portanto, esse grupo de países, que do ponto de vista do padrão de VCR tem interesses comuns (ou semelhantes), resulta ter um incentivo natural para atuar conjuntamente nas negociações da ALCA. Isto não significa que todos os países desse grupo atuem conjuntamente, mas sim que entre eles, em tese, há alguma viabilidade natural (pela conjugação de interesses comerciais) para uma atuação conjunta e sistemática nessas negociações comerciais. E como uma atuação em grupo pode ter alguma força de negociação diante dos Estados Unidos, então pode haver uma defesa da ALCA “light” por parte de todos, ou da maioria, dos países desse bloco natural.

Em terceiro lugar, há um outro subconjunto de países sul-americanos entre os aqui considerados, a saber, o Brasil (ver anexo 2), a Bolívia, o Chile e a Venezuela, que é dissimilar entre si e com todos os demais países aqui considerados. Cada um deles nesse segundo grupo, portanto, teria, em princípio, segundo a similaridade do padrão de VCR, incentivos para atuar de modo isolado, autocentrado e independente dos demais sul-americanos nas negociações da ALCA. A sua postura pró ou contra ALCA "light” obedece, assim, a uma contraposição entre conseqüências derivadas da dissimilaridade com o NAFTA e com os demais países ("relativo maior custo de integração comercial”) e que tendem à indução em favor da ALCA "light", com outros determinantes que não os considerados na presente análise.

Por exemplo, enquanto o Chile tem se posicionado a favor dos objetivos norte-americanos, refletindo a perspectiva de seu acordo de livre comércio com o NAFTA, a Venezuela tem recentemente adotado posturas antiamericanas, refletindo determinantes político-ideológicos conjunturais, mas não necessariamente fundamentados em seus interesses econômicos permanentes. O Brasil, por outro lado, tem tido uma postura ativa em favor da ALCA “light”, que reflete dois fatos básicos. Em primeiro lugar, reflete a dissimilaridade de seu padrão de VCR com o dos países do NAFTA, e que, portanto, implica um relativo elevado custo de integração comercial que, por hipótese, se manifestaria por completo numa ALCA “hard”. A esse fato básico também se adiciona a orientação de política externa brasileira, que busca uma consolidação com os parceiros do MERCOSUL e demais países sul-americanos, numa contraposição e diferenciação à liderança norte-americana na região.

Em vista disso, como há uma clara diferença entre os dois grupos de países sul-americanos aqui detectados, com os países do segundo grupo tendo, em princípio, nitidamente interesses comerciais autocentrados e independentes, resulta que as negociações da ALCA fomentam uma divisão de comportamento entre os países sul-americanos. Evidentemente, essa divisão e sua exata constituição depende das específicas vantagens e acesso a mercados oferecidas pelos países do NAFTA. Todavia, o que se quer salientar aqui é que parece ser mais fácil a cooptação desses países sul-americanos, pelo menos os de menor dimensão econômica (Bolívia, Chile e Venezuela), 
descritos como isolados ou independentes, pelos Estados Unidos na promoção de seus objetivos na ALCA.

Finalmente, há um terceiro grupo de países entre aqueles aqui considerados e que compõem o NAFTA, a saber, o México, os Estados Unidos e o Canadá, os quais são dissimilares com os demais países e, muito possivelmente, dissimilares entre si (na dependência do critério: Finger e Kreinin, ou correlação Spearman). No entanto, como eles já constituem um bloco regional de comércio (o NAFTA), esses países já estão "amarrados" entre si e tendem a atuar conjuntamente nas negociações da ALCA. A razão de sua defesa de uma ALCA “hard”, ao invés da "light" - cuja defesa também se poderia supor pela sua dissimilaridade com os países sul-americanos -, pode ser explicada pelo fato das economias sul-americanas serem expressivamente menores do que a dos Estados Unidos (e do conjunto do NAFTA). Isto implicaria, então, que em termos proporcionais a magnitude dos ajustamentos setoriais que serão potencialmente impostos aos Estados Unidos (e NAFTA) numa ALCA “hard” são, sem dúvida, menores do que aqueles que serão potencialmente impostos às economias sul-americanas. Assim sendo, os benefícios diretos e indiretos de integração numa ALCA “hard” serão, relativamente aos seus custos, maiores para os Estados Unidos (e NAFTA) do que o serão para os países sul-americanos. Muito possivelmente esse fato, de obtenção de um maior benefício relativo, também se constitui numa das razões da defesa insistente por uma “versão" de ALCA “hard” pelos Estados Unidos (e NAFTA).

\section{BIBLIOGRAFIA}

Adler, M. Specialization in the European coal and steal community. Journal of Common Market Studies, v. VIII, p. 175-191, 1970.

Aquino, A. Intra-industry trade and intra-industry specialization as concurrent sources of international trade in manufactures. Welwirtschaftliches Archiv, v. 114, p. 275-295, 1978.

Balassa, Bela. Trade liberalization and revealed comparative advantage. The Manchester Scholl of Economic and Social Studies, 33, p. 99-123, 1965.

. Tariff reductions and trade in manufactures among industrial countries. American Economic Review, v. 56, p. 466-473, 1967.

. Revealed comparative advantage revisited: an analysis of relative export shares of the industrial countries, 1953-1971. The Manchester Scholl of Economic and Social Studies, v. 61, n. 2, p. 259-266, 1977.

. The changing pattern of comparative advantage in manufacture goods. The Review of Economics and Statistics, v. 61, n. 2, p. 259-266, May 1979.

Bender, S.; Li, K. W. The changing trade and revealed comparative advantages of Asian and Latin American manufacture exports. Economic Growth Center (Econ. Dept., Yale University), Discussion Paper n. 843, March 2002a.

. A comparison of revealed comparative advantages between Asian and Latin American manufacture exports. Anais do Latin American Meeting of the Econometric Society, July 24-27 ${ }^{\text {Th }}$, $2002 \mathrm{~b}$.

Chow, P. C. Y. The revealed comparative advantage of the East Asian NIC's. The International Trade Journal, v. V, n. 2, p. 235-262, Winter 1990.

Finger, J. M.; Kreinin, M. E. A measure of export similarity and its possible uses. The Economic Journal, v. 89, p. 905-912, December 1979.

Fudenberg, D.; Tirole, J. Game theory. Cambridge, Mass: MIT Press, 1991.

Fukurora, J. Adjustment in the Japanese textile industry. 1990. PhD Thesis, University of Sussex. 
Greenaway, D.; Milner, C. The economics of intra industry trade. Oxford: Blackwell, 1986. . Trade and industrial policy in developing countries. The Macmillan Press, 1993.

Hillman, A. L. Observations on the relation between revealed comparative advantage and comparative advantage as indicated by pre-trade relative prices. Welwirtschaftliches Archiv, v. 116, p. 315-321, 1980.

Jank, Marcos; Tachinardi, M. H.; Arashiro, Z. A explosão de acordos preferenciais. Informativo do Grupo de Conjuntura Internacional da USP, Ano 6, n. 21, p. 12-13, Maio-Jun. 2004.

Kreinin, M. E.; Plummer, M. G. Natural economic blocs: an alternative formulation. The International Trade Journal, v. VIII, n. 2, p. 193-205, Summer 1994.

Kellman, M.; Schroder, T. The export similarity index: some structural tests. The Economic Journal, v. 93, n. 369, p. 193-198, March 1983.

Lee, Jaimin. Comparative advantage in manufacturing as a determinant of industrialization: the Korean case. World Development, v. 23, n. 7, p. 1195-1214, 1995.

Marchese, S.; Simone, F. N. de Monotonicity of indices of revealed comparative advantage: empirical evidence on Hillman's condition. Weltwirtschaftliches Archiv, v. 125, n. 1, p. 158-167, 1989.

Memedovic, Olga. On the theory and measurement of comparative advantage. Tinbergen Institute Research Series, n. 65, Amsterdam, 1994.

OCDE. Structural adjustment and economic performance. Paris: OECD, 1987.

Pomfret, Richard. The impact of EEC enlargement on non-member mediterranean countries' exports to the EEC. The Economic Journal, v. 91, n. 363, p. 726-729, September 1981.

Rana, P. B. Shifting comparative advantage among Asian and pacific countries. The International Trade Journal, v. IV, n. 3, p. 243-258, Spring 1990.

Salazar-Xirinachs, J. M. Proliferation of sub-regional trade agreements in the Americas: an assessment of key analytical and policy issues. Journal of Asian Economics, v. 13, p. 181-212, 2002.

UNIDO. Industrial demand-supply balance database. Geneva, 2002.

Vollrath, T. L. A theoretical evaluation of alternative trade intensity measures of revealed comparative advantage. Weltwirtschaftliches Archiv, v. 127, n. 2, p. 265-280, 1991. 


\section{ANEXO 1}

Tabela A-1 - Classificação e composição de indústrias manufatureiras segundo ISIC

\begin{tabular}{|c|c|}
\hline DISCRIMINAÇÃO ISIC 3-DÍGITOS & COMPOSIÇÃO COM ISIC 4-DÍGITOS \\
\hline 311 - Produtos Alimentícios & $3111 ; 3112 ; 3113 ; 3114 ; 3115 ; 3116 ; 3117 ; 3118 ; 3119$ \\
\hline 312 - Produtos Alimentícios não classificados & $3121 ; 3122$ \\
\hline 313 - Indústria de Bebidas & $3131 ; 3132 ; 3133 ; 3134$ \\
\hline 314 - Indústria de Tabaco & 3140 \\
\hline 321 - Indústria Têxtil & $3211 ; 3212 ; 3213 ; 3214 ; 3215 ; 3219$ \\
\hline 322 - Produtos Têxteis Acabados & 3220 \\
\hline 323 - Couro e Indústria de Couro & $3231 ; 3232 ; 3233$ \\
\hline 324 - Calçados & 3240 \\
\hline 331 - Produtos de Madeira & $3311 ; 3312 ; 3319$ \\
\hline 332 - Mobília e Ornamento & 3320 \\
\hline 341 - Celulose, Papel e Produtos de Papel & $3411 ; 3412 ; 3419$ \\
\hline 342 - Impressão e Publicação & 3420 \\
\hline 351 - Indústria Química & $3511 ; 3512 ; 3513$ \\
\hline 352 - Produtos Químicos & $3521 ; 3522 ; 3523 ; 3529$ \\
\hline 353 - Petróleo Refinado & 3530 \\
\hline 354 - Petróleo e Indústria Carvoeira & 3540 \\
\hline 355 - Artigos de Borracha & $3551 ; 3559$ \\
\hline 356 - Indústria Plástica & 3560 \\
\hline 361 - Porcelana e Cerâmica & 3610 \\
\hline 362 - Vidro e Indústria de Vidro & 3620 \\
\hline 369 - Produtos Minerais Não-Metálicos & $3691 ; 3692 ; 3699$ \\
\hline 371 - Ferro e Indústria Básica do Aço & 3710 \\
\hline 372 - Indústria Básica de Metais Não-Ferrosos & 3720 \\
\hline 381 - Produtos de Metal & $3811 ; 3812 ; 3813 ; 3819$ \\
\hline 382.1 - Maquinário, exceto maquinário elétrico & $3821 ; 3822 ; 3823$ \\
\hline 382.2 - Máquinas e Equipamentos & $3824 ; 3825 ; 3829$ \\
\hline 383.1 - Maquinário Elétrico & 3831 \\
\hline 383.2 - Ferramentas Elétricas & $3832 ; 3833 ; 3839$ \\
\hline 384 - Equipamento de Transporte & $3841 ; 3842 ; 3843 ; 3844 ; 3845 ; 3849$ \\
\hline 385 - Equipamento Científico e Profissional & $3851 ; 3852 ; 3853$ \\
\hline 390 - Outras Indústrias Manufatureiras & 3901; 3902; 3903; 3909 \\
\hline
\end{tabular}

\section{ANEXO 2 - ANÁliSE DA SIMILARIDADE DO PADRÃO DE VCR DE PAÍSES DAS AMÉRICAS COM A INCLUSÃO DO BRASIL}

Neste anexo 2 reproduzimos a análise de correlação do padrão de VCR dos países das Américas com a inclusão do Brasil, num total de 12 países. Neste sentido, efetuamos uma adaptação própria da nomenclatura NCM ao código ISIC (3 dígitos), que resultou em 28 setores, e devido à 
disponibilidade de dados de exportações do Brasil, o período de análise compreende somente o período de 1990 a 1999. O padrão de VCR do Brasil está exposto na Tabela A-2, e cuja análise revelou as seguintes características dominantes para o padrão de exportação brasileiro nos anos 90:

(1) Uma característica saliente é a da estabilidade do padrão de VCR no período;

(2) Os setores com VCR são, justamente, os setores e indústrias intimamente relacionadas (ou baseados) a produtos agropecuários $(311,312,314,323$ e 324), a produtos básicos e minerais (361, 369, 371 e 372) e a produtos de extração "florestal” (331, 341, 355). Uma exceção a esse padrão é o da indústria plástica (356);

(3) Há dois setores que apresentam ganho expressivo e sistemático nos anos 1990 (setor 332 - mobília e ornamento - e o setor 384 - equipamento de transporte), embora não estejam entre os setores de VCR. Há também dois setores (321 e 322), relacionados à indústria têxtil, que apresentam perda expressiva e sistemática de desempenho exportador (e perda de VCR) no período;

(4) Em geral, nos setores de maior densidade tecnológica (tais como: 351, 352, 382, 383, 384, 385), à exceção do setor 384 (equipamentos de transporte), o desempenho exportador do Brasil é visivelmente não-satisfatório.

Tabela A-2 - Índices de VCR (Balassa) do Brasil - Adaptação ao código ISIC

\begin{tabular}{lcccc}
\hline SETORES I SUBPERÍODOS & 1990 - 1992 & $1993-1995$ & $1996-1998$ & $1997-1999$ \\
\hline 311 - Produtos Alimentícios & 3,39 & 3,56 & 4,18 & 4,53 \\
312 - Prod. Alimentícios não classificados & 1,95 & 2,38 & 2,24 & 2,39 \\
313 - Indústria de Bebidas & 0,32 & 0,53 & 0,42 & 0,34 \\
314 - Indústria de Tabaco & 5,85 & 6,25 & 9,03 & 8,37 \\
321 - Indústria Têxtil & 0,74 & 0,54 & 0,48 & 0,44 \\
322 - Produtos Têxteis Acabados & 0,76 & 0,81 & 0,53 & 0,47 \\
323 - Couro e Indústria de Couro & 2,61 & 2,65 & 3,51 & 3,55 \\
324 - Calçados & 6,31 & 6,51 & 6,08 & 6,03 \\
331 - Produtos de Madeira & 1,25 & 2,00 & 2,01 & 2,24 \\
332 - Mobília e Ornamento & 0,32 & 0,91 & 0,92 & 0,94 \\
341 - Celulose, Papel e Produtos de Papel & 1,51 & 1,85 & 1,77 & 1,88 \\
342 - Impressão e Publicação & 0,09 & 0,12 & 0,09 & 0,11 \\
351 - Indústria Química & 0,49 & 0,44 & 0,52 & 0,52 \\
352 - Produtos Químicos & 0,63 & 0,73 & 0,85 & 0,83 \\
353 \& 354 - Ind. do Petróleo e do Carvão & 0,89 & 0,92 & 0,43 & 0,44 \\
355 - Artigos de Borracha & 1,26 & 1,51 & 1,65 & 1,65 \\
356 - Indústria Plástica & 1,45 & 1,59 & 1,40 & 1,34 \\
361 - Porcelana e Cerâmica & 2,00 & 2,69 & 2,64 & 2,71 \\
362 - Vidro e Indústria de Vidro & 0,40 & 0,55 & 0,58 & 0,63 \\
369 - Produtos Minerais Não-Metálicos & 0,86 & 1,03 & 1,34 & 1,50 \\
371 - Ferro e Indústria Básica do Aço & 3,61 & 3,09 & 2,84 & 2,71 \\
372 - Ind. Básica de Metais Não-Ferrosos & 2,46 & 2,09 & 1,78 & 1,77 \\
381 - Produtos de Metal & 0,71 & 0,77 & 0,77 & 0,74 \\
382 - Máq. e Equip., exceto elétricos & 0,58 & 0,61 & 0,59 & 0,59 \\
383 - Maquinário e Ferramentas Elétricos & 0,34 & 0,28 & 0,26 & 0,27 \\
384 - Equipamento de Transporte & 0,49 & 0,53 & 0,69 & 0,74 \\
385 - Equip. Científico e Profissional & 0,29 & 0,24 & 0,20 & 0,24 \\
390 - Outras Indústrias Manufatureiras & 1,15 & 1,00 & 1,35 & 1,18 \\
TOTAL - SETORES DE VCR & 13 & 14 & 14 & 14 \\
\hline
\end{tabular}


O padrão de VCR do Brasil acima exposto também fica evidente quando adotamos a classificação de 1-dígito da OCDE. Neste caso, a adaptação das exportações brasileiras nos anos 1990 a esse código gera o padrão de VCR exposto na Tabela A-3:

Tabela A-3 - Indicadores de VCR (Balassa) do Brasil - Código OCDE

\begin{tabular}{lcccc}
\hline INDÚSTRIASIPERIODO & $1990-1992$ & $1993-1995$ & $1996-1998$ & $1997-1999$ \\
\hline 1 RECURSO-INTENSIVAS & $\mathbf{2 , 3 0}$ & $\mathbf{2 , 4 9}$ & $\mathbf{2 , 6 6}$ & $\mathbf{2 , 7 9}$ \\
2 TRABALHO - INTENSIVAS & $\mathbf{1 , 1 1}$ & $\mathbf{1 , 1 0}$ & $\mathbf{1 , 0 2}$ & 0,95 \\
3 ESCALA - INTENSIVAS & 0,90 & 0,87 & 0,93 & 0,94 \\
4 BENS DIFERENCIADOS & 0,56 & 0,53 & 0,52 & 0,52 \\
5 BASEADAS EM CIÊNCIA & 0,23 & 0,27 & 0,26 & 0,27 \\
\hline
\end{tabular}

Portanto, segundo a classificação de 1-dígito da OCDE o Brasil apresenta VCR em indústrias recurso-intensivas e trabalho-intensivas, e embora não tenha VCR, também tem um desempenho razoável em indústrias escala-intensivas (“equipamentos de transporte”). No geral, contudo, o padrão de VCR é tipicamente sul-americano, mas que, talvez como reflexo da perda de dinamismo em têxteis, em razão da concorrência asiática (China) nos mercados internacionais, vem perdendo sistematicamente desempenho exportador em indústrias trabalho-intensivas. Finalmente, uma outra característica é uma relativamente elevada, mas não completa, estabilidade no padrão de VCR do Brasil nos anos 1990.

Quanto às correlações Spearman entre os padrões de VCR de países a partir da adaptação efetuada entre o código ISIC e o código NCM, que possibilitou a inclusão do Brasil na amostra de países das Américas, estas estão dispostas na Tabela A-4: $:^{15}$

Tabela A-4

\begin{tabular}{|c|c|c|c|c|c|c|c|c|c|c|c|c|}
\hline & \multicolumn{4}{|c|}{ ARGENTINA } & \multicolumn{4}{|c|}{ BOLÍVIA } & \multicolumn{4}{|c|}{ BRASIL } \\
\hline & $90-92$ & 93-95 & $96-98$ & $97-99$ & $90-92$ & 93-95 & $96-98$ & $97-99$ & 90-92 & 93-95 & $96-98$ & $97-99$ \\
\hline ARGENTINA & $X X X$ & $X X X$ & $x X X$ & $x X X$ & 0,23 & $0,42^{*}$ & 0,17 & 0,12 & $0,35^{*}$ & 0,18 & 0,17 & 0,22 \\
\hline BOLÍVIA & 0,23 & $0,42^{*}$ & 0,17 & 0,12 & $x x x$ & $x x x$ & $X X X$ & $X X X$ & $-0,004$ & 0,16 & 0,26 & 0,24 \\
\hline BRASIL & $0,35^{*}$ & 0,18 & 0,17 & 0,22 & $-0,004$ & 0,16 & 0,26 & 0,24 & $x x x$ & $X X X$ & $\mathrm{XXX}$ & $X X X$ \\
\hline CANADÁ & $-0,07$ & $-0,07$ & 0,21 & 0,20 & $-0,13$ & $-0,27$ & 0,05 & 0,10 & $-0,11$ & $-0,11$ & $-0,11$ & $-0,06$ \\
\hline CHILE & $0,42^{*}$ & 0,26 & $0,43^{*}$ & $0,51^{*}$ & 0,20 & $-0,13$ & 0,28 & 0,30 & 0,31 & 0,28 & 0,21 & 0,24 \\
\hline COLÔMBIA & $0,50^{*}$ & $0,56^{*}$ & $0,40^{*}$ & $0,38^{*}$ & 0,24 & $0,38^{*}$ & $-0,07$ & $-0,14$ & 0,28 & $0,34^{*}$ & $-0,06$ & $-0,01$ \\
\hline EQUA & 0,16 & 0,09 & 0,19 & 0,20 & 0,35 & $0,32^{*}$ & 0,22 & 0,15 & 0,25 & $0,35^{*}$ & 0,22 & 0,24 \\
\hline MÉXICO & $0,58^{*}$ & $0,54^{*}$ & $-0,33^{*}$ & $-0,42^{*}$ & 0,001 & $-0,01$ & $-0,11$ & $-0,08$ & 0,11 & 0,15 & $-0,30$ & $-0,34^{*}$ \\
\hline PERU & $0,49^{*}$ & $0,43^{*}$ & 0,16 & 0,15 & 0,24 & 0,19 & $0,45^{*}$ & $0,36^{*}$ & 0,26 & 0,24 & 0,05 & 0,11 \\
\hline URUGUAI & $0,51^{*}$ & $0,47^{*}$ & $0,46^{*}$ & $0,46^{*}$ & $0,38^{*}$ & $0,39^{*}$ & 0,29 & 0,21 & 0,30 & 0,22 & $0,32^{*}$ & $0,35^{*}$ \\
\hline U.S. & $-0,37^{*}$ & $-0,38^{*}$ & $-0,31$ & $-0,25$ & $-0,14$ & $-0,10$ & $-0,17$ & $-0,14$ & $-0,33^{*}$ & $-0,41^{*}$ & $-0,31$ & $-0,30$ \\
\hline VENEZUELA & $0,35^{*}$ & $0,33^{*}$ & $0,43^{*}$ & $0,49^{*}$ & $-0,27$ & $-0,10$ & $-0,04$ & $-0,17$ & $0,37^{*}$ & 0,31 & 0,27 & 0,30 \\
\hline
\end{tabular}

15 Note-se que, pelo fato de agora serem somente 28 as indústrias consideradas, as correlações constantes na Tabela A-4, mesmo que próximas, não são exatamente comparáveis com as da Tabela 4 (com 31 indústrias). 
Tabela A-4 (cont.)

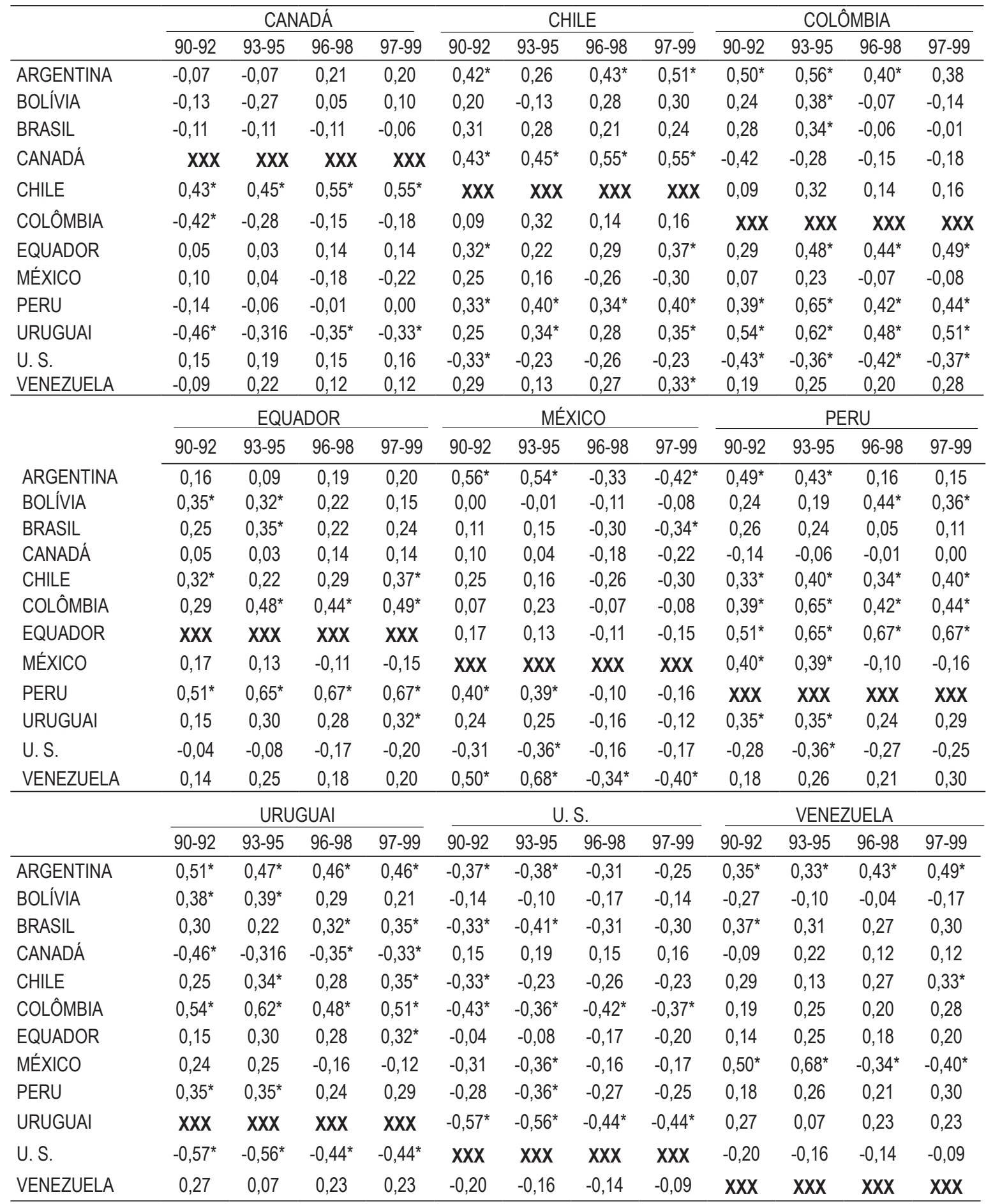

A análise das correlações Spearman constantes na Tabela A-4 mantém, quase que por inteiro, a análise anteriormente efetuada com base na Tabela 4 (no texto principal) em relação a 11 países das Américas sem o Brasil. Assim sendo, concentraremos aqui apenas a análise do caso brasileiro. 
Em primeiro lugar, as correlações entre o padrão de VCR do Brasil e o dos países latino-americanos são em geral positivas, mas todas elas são baixas ou nulas e poucas significantes. As correlações com o Canadá e os Estados Unidos são todas elas negativas e algumas significantes. As correlações com o México seguem o padrão constatado para os outros países sul-americanos: também se alteram para negativas após 1995.

Em suma, o Brasil não tem similaridade de padrão de VCR com nenhum dos países das Américas aqui considerados. Portanto, uma integração comercial entre o Brasil e os países das Américas na ALCA também tende a ter um relativo maior custo econômico de integração comercial. Por outro lado, a dissimilaridade do padrão de VCR do Brasil com todos os demais países aqui considerados também o diferencia daquele conjunto de países sul-americanos que têm uma relativa similaridade entre eles e que formam um bloco natural de países (Argentina, Colômbia, Equador, Peru e Uruguai). Assim sendo, por este critério de similaridade, o Brasil se encontra numa situação muito semelhante àquela atribuída ao conjunto de países anteriormente caracterizados como países "diferenciados" ou "independentes" (Bolívia, Chile e Venezuela). Note-se também que a dissimilaridade entre o Brasil com os seus sócios no MERCOSUL (Argentina e Uruguai; países "similares” entre si) resulta que a integração comercial do MERCOSUL tem um relativo maior custo econômico de integração comercial. E tal como no caso dos países sul-americanos com relação ao NAFTA (mas, evidentemente, em menor proporção), a menor dimensão econômica da Argentina e Uruguai em relação ao Brasil implica que os custos de integração são proporcionalmente maiores para a Argentina e Uruguai do que o são para o Brasil.

Finalmente, pela Tabela A-4, e adotando os mesmos critérios anteriormente utilizados para seleção de países com correlação “forte e estável” entre si ao longo dos anos 1990, obtém-se o seguinte conjunto de correlações (fortes e estáveis): Argentina-Chile, Argentina-Colômbia, Argentina-Uruguai, Canadá-Chile, Colômbia-Equador, Colômbia-Peru, Colômbia-Uruguai, e Equador-Peru. Portanto, a composição dos países candidatos a formarem um bloco natural resulta, inicialmente, no seguinte conjunto de países: Argentina (3), Canadá (1), Chile (2), Colômbia (4), Equador (2), Peru (2) e Uruguai (2). A seguir, adotando-se os mesmos procedimentos para a exclusão daqueles países com o menor número de correlações fortes e estáveis nesse conjunto inicial, tem-se o seguinte conjunto (intermediário) de países: Argentina (3), Chile (1), Colômbia (4), Equador (2), Peru (2) e Uruguai (2). Finalmente, esse conjunto (intermediário) dá origem ao conjunto final de países: Argentina (2), Colômbia (4), Equador (2), Peru (2) e Uruguai (2). Note-se que esse conjunto final de países não satisfaz a definição estrita de bloco natural de países anteriormente adotada. Isso ocorre porque há um subconjunto de países (Argentina, Equador, Peru e Uruguai) nesse grupo final que tem $50 \%$ do total das quatro possíveis correlações fortes e estáveis (de cada país com os demais países nesse grupo final). Embora esse porcentual seja elevado, ele não satisfaz o critério anterior de exigir-se pelo menos $2 / 3$ do total possível de relações fortes e estáveis entre os países do grupo final. Entretanto, esse conjunto final constitui-se no agrupamento de países mais próximo que se pode alcançar daquela definição de bloco natural de países, isto é, a partir da correlação dos padrões de VCR obtido com essa nova classificação adaptada (ISIC e NCM) de setores manufatureiros. Cabe também observar que esse agrupamento final de países guarda estreita identidade com o conjunto de países bloco natural anteriormente obtido. 